\title{
Family Planning and Development: Aggregate Effects of Contraceptive Use*
}

\author{
Tiago Cavalcanti \\ University of Cambridge and \\ Sao Paulo School of Economics - FGV \\ tvdvc2@cam.ac.uk \\ Cezar Santos \\ Bank of Portugal and \\ FGV EPGE \\ cezarsantos.econ@gmail.com
}

Georgi Kocharkov

Deutsche Bundesbank

georgi.kocharkov@bundesbank.de

\begin{abstract}
What is the role of family planning interventions on fertility, savings, human capital investment, and development? To examine this, endogenous unwanted fertility is embedded in an otherwise standard quantity-quality overlapping generations model of fertility and growth. The model features costly fertility control and families can (partially) insure against a fertility risk by using costly modern contraceptives. In the event of unexpected pregnancies, households can also opt to abort some pregnancies, at a cost. Given the number of children born, parents decide how much education to provide and how much to save out of their income. We fit the model to Kenyan data, implement several family planning policies and decompose their aggregate effects. Our results suggest that with a small government budget (say, up to 0.5 percent of GDP), family planning interventions might be more cost-effective in improving longrun living standards than policies that subsidise basic education.
\end{abstract}

KEYWORDS: education, income per capita, contraception, abortion JEL CLASSIFICATION: E24, I15, J13, O11.

\footnotetext{
* We thank two anonymous referees, the editor Frederic Vermeulen, for useful comments. We also benefited from discussions and conversations with Kenneth Arrow, Vasco Carvalho, Francesco Caselli, Oded Galor, Paula Gobbi, Pedro Gomes, Jeremy Greenwood, Nezih Guner, Joan Llull, Alex Monge-Naranjo, Todd Schoellman, Michèle Tertilt, David Weil, Gustavo Ventura, and seminar participants at numerous institutions. Financial support is gratefully acknowledged from the Coordenação de Aperfeiçoamento de Pessoal de Nível Superior-Brasil (CAPES) - Finance Code 001 and Faperj. The usual disclaimer applies. The opinions expressed in this paper are those of the authors and do not necessarily reflect the views of the Bank of Portugal and the Deutsche Bundesbank.
} 
"Each family tries to come as close as possible to its desired number of children... Families with excess children consume less of other goods, especially of goods that are close substitutes for the quantity of children. Because quality seems like a relatively close substitute for quantity, families with excess children would spend less on each child than other families with equal income and tastes. Accordingly, an increase in contraceptive knowledge would raise the quality of children as well as reduce their quantity." (Becker, 1960, p. 218)

\section{Introduction}

What is the role of family planning interventions on fertility, savings, human capital investment, and development? Since Malthus (1798), population dynamics have been at the core of long-run economic analysis, and recent growth models (cf., Galor and Weil, 2000) have continued to emphasise this. A common view in economic growth theory is that high fertility mainly reflects desired family size and that parents are able to achieve their fertility target (cf., Barro and Becker, 1989). From this perspective, fertility changes are driven by parents' demand for children (e.g., quantity-quality substitution or declining infant mortality) and supply factors, such as family-planning interventions, should have no impact on family size. However, in reality, sometimes people want to have the children they conceive, and sometimes they do not. Though this statement may sound rather terse, there is evidence to back it up. ${ }^{1}$ According to Bongaarts (2016) about 39 percent of annual developing-world pregnancies are unplanned, and roughly half of these end in induced abortions. In fact, in some countries, there is a substantial gap between realised fertility and wanted fertility; and this gap is also larger for relatively poorer households. ${ }^{2}$ The fact that contraceptive methods are costly and individuals sometimes resort to abortions in order to control their family sizes corroborates this idea. In sum, there seems to be a random aspect to fertility. ${ }^{3}$

When parents have children, a natural step that follows is to provide them with care and education. Needless to say, while children bring a variety of inestimable benefits to parents, they are costly both in terms of goods and time. For instance, education costs money: tuition fees, books, transportation, and foregone wages that could come from child labor. Education and childrearing are also costly in terms of time (e.g., parents take care of their children when they are sick).

When added together, the statements in the previous two paragraphs (i.e., the randomness of fertility and the cost of child care and education) imply that the educational attainment of children in practice may not be as high as in a situation in which parents

\footnotetext{
${ }^{1}$ We provide detailed empirical facts on this issue in Section 3.

${ }^{2}$ Wanted fertility is defined as the age-specific hypothetical fertility under the condition that all women's fertility preferences were perfectly realised.

${ }^{3}$ In a time when modern contraceptive methods were not available Malthus (1798) stated that "the passion between the sexes is necessary and will remain nearly in its present state" and the population would grow if it was not checked by the scarcity of food and its consequences, such as infectious diseases; or by voluntary restraint, such as abstaining from early marriages (cf., Voigtländer and Voth, 2013). Dasgupta (2000) argues that except under conditions of extreme nutritional stress, nutritional status does not appear to affect fecundity.
} 
could perfectly control their fertility. In the aggregate, this may imply that human capital may be lower due to the randomness of family size. In addition, if poor households have lower control of their family size, this can lead to more heterogeneity in fertility with consequences on the level and persistence of inequality in education and income. ${ }^{4}$ This could also have an effect on a country's production output since workers will have lower skills. The natural question is whether or not such effects are important and how family planning interventions affect the fertility gap. ${ }^{5}$ This paper addresses these questions.

Although the ability to control family size is present even in primitive societies through abortion, infanticide, and other practices, and some very effective contraceptive methods have been available for more than 100 years (cf., Himes, 1936), there still exists a gap between realised and desired fertility in developing countries. This gap is negatively correlated with income (see Tables A1 and A2 in the Online Appendix). For instance, the proportion of women with unmet need for contraception could be as high as 40 percent in the Democratic Republic of Congo (cf., The World Bank, 2010) and it is in general higher for low income households. ${ }^{6}$ The empirical evidence also shows that there exists a significant negative relationship between the fertility gap and educational attainment across countries. That is, when fertility is closer to its desired level, educational attainment is higher. Moreover the fertility gap is lower in countries where contraceptive use is more widespread. This last correlation holds even when country-fixed effects, which control for main religion and other cultural factors, and the level of development are taken into account (see Table 1). The negative relationship between contraceptive use and unwanted fertility is also observed using individual level data for women in Kenya (see Table 3).

We develop a general macroeconomic equilibrium model to assess the role of family planning interventions on development. The model economy is populated by overlapping generations. Households make a consumption and savings decision and imperfectly choose how many (quantity) children they want to have (demand factors). However, households may have more pregnancies than desired due to unexpected fertility shocks. Families can partially insure against this fertility risk by using costly contraception (supply factors). In the event of unexpected pregnancies, households can opt to abort some of them, but abortion is costly. Given the number of children born, parents decide how much (quality) education to provide them. In our model, the fertility gap is consequence of a series of factors such access to modern contraceptives, abortion law and social norms, which map into utility costs of abortion and use of modern contraceptives. Schooling is costly in terms of consumption goods and children rearing is costly in terms of time. These

\footnotetext{
${ }^{4}$ Using Quebec data from the 16th to the 18th century, Galor and Klemp (2015) explore the absence of reliable contraceptives in the determination of fertility to show that moderate fecundity and thus predisposition towards investment in child quality was conducive to long-run reproductive success, reflecting the negative effect of higher fecundity on the education of each offspring.

${ }^{5}$ Family planning interventions may be justified even when the overall fertility rate is below the replacement rate, but when some households have a fertility rate above their desired level.

${ }^{6}$ The median of unmet need for contraception for developing countries is 22 percent. Unmet need for contraception is defined (cf., The World Bank, 2010) as the "proportion of currently married women who do not want any more children but are not using any form of family planning or currently married women who want to postpone their next birth for two years but are not using any form of family planning".
} 
features allow us to map indicators (e.g., the contraceptive prevalence rate, abortion rate, unwanted fertility, and unmet need for family planning) of reproductive behaviour from the data into the model and to study different family planning interventions. On the production side of the economy, there is a standard representative firm which uses labor and capital as inputs to produce final goods. We solve for a stationary equilibrium.

The model parameters are fitted to match statistical moments for the Kenyan economy, a country in which the average fertility gap is 1.2 children, which is above the average (0.87) for all developing countries in our dataset. The average gap hides important heterogeneity since the gap between realised and wanted fertility is approximately 2 children for parents with a primary degree and 0.6 for parents with more than 12 years of schooling. In the baseline economy there is substantial heterogeneity in education and income. We are able to replicate the fertility pattern (levels and heterogeneity) and the gap between realised and wanted fertility observed in the data. We show that the way in which family planning policies affect fertility in our model is consistent with the estimates reported in the microeconometric literature, which gives us confidence to further explore the impacts of such policies on the economy. We then assess the importance of family-planning interventions on education, inequality, and income per capita. Counterfactual exercises are implemented to shed some light on the quantitative importance of contraception use. For instance, in a world without fertility risk (i.e. with no unwanted pregnancies), educational attainment would be higher by about 1.1 extra year of education. Together with a rise in the capital stock, this leads to a hike in income per capita of about 13 percent. We also investigate several policies commonly used, including policies targeted at the poor. We show that given a small government budget (say 0.5 percent of GDP), family planning interventions (e.g., subsidising the price of modern contraceptives) are more cost-effective in improving living standards than policies that subsidise education.

We decompose the effect of family planning interventions on the economy into three channels: a general equilibrium effect due to price movements, a wanted fertility channel since desired fertility may change with policies, and the response of parents investment in education of their children. We show that to fully understand the effects of family planning policies on individual outcomes it is important to perceive the response of households in terms of desired fertility to each policy, as well as the interaction of this response with households investment decisions. Families target a higher wanted fertility rate when the fertility risk of unwanted pregnancies is reduced. This can mitigate some of the effects of family planning policies on reproductive behaviour, investment, and income levels.

The remainder of this paper is divided into six additional sections. The next section describes the related literature on the topic and places our contribution. Some empirical facts are documented in Section 3. Section 4 describes the model economy, which is used for quantitative analysis. Section 5 fits model parameters to the data, and Section 6 provides the quantitative analysis to measure the aggregate effects of family planning interventions on development. Section 7 contains concluding remarks. There is also a companion Online Appendix with the description of the data and some robustness exercises. ${ }^{7}$

\footnotetext{
${ }^{7}$ The Online Appendix can be found at https://sites.google.com/site/czrsantos/research.
} 


\section{Related Literature}

Our research is related to a literature on the relationship between fertility and development. Most of the papers in this literature focus on the joint evolution of economic and demographic processes (cf., Barro and Becker, 1989; de la Croix and Doepke, 2003; Galor and Weil, 2000) represented by a negative relationship between fertility and income. ${ }^{8}$ The main idea is that when income rises the opportunity cost of raising children rises and parents decrease their family size and invest more in each child. This is the quantity-quality trade-off, which depends on the income elasticity of the quantity and quality of children, postulated and explained intuitively by Becker (1960), which has been the dominant theoretical framework in the economics of fertility over the past decades (cf., Doepke, 2015). Economists have used this framework to understand the dynamics of economic development and whether or not fertility choice can help to explain such dynamics. ${ }^{9}$ Becker (1960) does discuss in detail the importance of contraceptive methods in controlling family size, but birth control techniques are not mentioned in his subsequent work (cf., Barro and Becker, 1989; Becker and Lewis, 1973). ${ }^{10}$ Our interpretation is that the discussion of most of these articles focus on fertility in developed countries, such as the United States, where these contraceptive methods are affordable and readily available to the public. In addition, there is public awareness about their effectiveness in controlling pregnancies, and therefore the realised number of children is very close to the desired one. Our view is that this might not be the case for some developing countries, and this seems to be backed by the empirical evidence. In developing countries even when contraceptives can be obtained at low cost in public clinics, for example, they are often stocked out (cf., Ashraf, Field, and Lee, 2014). To the best of our knowledge our paper is the first to consider explicitly fertility shocks, costly contraception choice, and abortion in a model of growth and development with endogenous population growth, and to investigate the aggregate effects of family planning interventions. ${ }^{11}$ Baudin, de la Croix, and Gobbi (2016) also consider unwanted fertility by assuming that a share of couples cannot control fertility, but this differs from our approach since we assume that fertility control is costly, and the lack of ability to perfectly control pregnancies is derived from economic incentives. They investigate a family

\footnotetext{
${ }^{8}$ Our model can generate a negative correlation between fertility and income even when the desired family size is constant. This can happen because as income rises, modern contraceptive methods become relatively cheaper and the gap between realised and wanted fertility decreases.

${ }^{9}$ See, for instance, de la Croix and Doepke (2003) and Vogl (2016).

${ }^{10}$ Doepke (2015) states that "In the sense that the lack of knowledge of birth control among poorer households is assumed rather than derived from economic incentives, Becker's 1960 paper does not yet go all the way in founding fertility choice in economics." We provide economic foundation for that based on costly contraceptives and we show that this may be quantitatively important in some developing countries.

${ }^{11}$ Strulik (2017) also considers costly contraception in a model of growth. He abstracts from fertility shocks and heterogeneity among households, while we explore such dimensions. He focuses on the role of modern contraceptives in the fertility transition, and we concentrate on the impact of family planning interventions on individual and aggregate outcomes. The role of modern contraceptives in the fertility transition is also studied by Bhattacharya and Chakraborty (2017). In a recent article, de Silva and Tenreyro (2019) investigates the role of changes in social norms in the fertility transition and how population policies might have changed such norms. On this, see also Beach and Hanlon (2019). We see our paper complementary to theirs.
} 
planning policy which sets the percentage of couples able to control their fertility to one. Ashraf, Weil, and Wilde (2013) also study the effects of policies which reduce fertility on investment and output per capita. Fertility is exogenous in their framework, and they feed different population paths into a growth model to asses the impact of each on output dynamics.

Our general idea relies on the assumption that family planning interventions have a first-order effect on fertility decisions. There is a bulk of evidence supporting this. ${ }^{12}$ For instance, Bloom, Canning, Fink, and Finlay (2009) show that removing legal restrictions on abortion significantly reduces fertility and that this has a positive impact on female labor force participation. Using an experiment in Zambia, Ashraf, Field, and Lee (2014) show that the local average treatment effect estimation implies that use of family planning services during about two years of the experiment was associated with a 27 percent reduction in births. Using variation in the timing and location of the Profamilia program in Colombia, Miller (2010) finds that availability of modern contraceptives allowed women to postpone their first birth and to have about 5 percent fewer children in their lifetime.

Our model helps to rationalise these findings since we integrate demand and supply factors in the determination of fertility, which is not possible in a standard quantity-quality fertility model. This paper therefore provides a bridge between the macro literature on fertility and growth and the empirical micro literature on family planning interventions, fertility, and human capital outcomes. In addition, with our framework it is possible to run and to evaluate a variety of counterfactual policies, not necessarily available in control trial experiments, and to disentangle different channels, such as the importance of general equilibrium effects. Therefore, we believe our paper is an important contribution to the literature on family planning policy and development, filling an existing gap with farreaching implications for policies.

\section{Facts}

In this section we describe some macro (Subsection 3.1) and micro (Subsection 3.2) empirical facts which motivate our work.

\subsection{Cross-Country Facts}

Table 1 shows the regression results in which the dependent variable is the gap between actual and wanted fertility, and the explanatory variable of interest is the percentage of women who have ever used modern contraceptive methods. ${ }^{13}$ We have an unbalanced panel since the Demographic Health Surveys (DHS) from USAID, which contain information on the fertility gap and contraceptive use across countries, are implemented in

\footnotetext{
${ }^{12}$ Subsection 5.3 summarises some studies on the effects of family planning policies on fertility. See also de Silva and Tenreyro (2017).

${ }^{13}$ The descriptions of all data sources, definition of the variables, summary statistics, and simple correlations are reported in the companion Online Appendix.
} 
Table 1: Relationship between unwanted fertility and the use of modern contraceptive methods - Cross country Analysis.

\begin{tabular}{|c|c|c|c|c|c|c|}
\hline & & ependent va & iable: Un & anted fert & ty (fertility & \\
\hline & (1) & (2) & (3) & (4) & (5) & (6) \\
\hline $\begin{array}{l}\% \text { of women who ever used } \\
\text { modern contr. methods }\end{array}$ & $\begin{array}{l}-0.0015 \\
(0.0027)\end{array}$ & $\begin{array}{l}-0.0099^{* * *} \\
(0.0033)\end{array}$ & $\begin{array}{l}-0.0048 \\
(0.0040)\end{array}$ & $\begin{array}{l}-0.0057 \\
(0.0042)\end{array}$ & $\begin{array}{c}-0.0136^{* * *} \\
(0.0049)\end{array}$ & $\begin{array}{l}-0.0089^{*} \\
(0.0046)\end{array}$ \\
\hline Log of per capita GDP & $\begin{array}{l}-0.0134 \\
(0.0641)\end{array}$ & $\begin{array}{l}-0.0153 \\
(0.1544)\end{array}$ & $\begin{array}{c}0.0499 \\
(0.1761)\end{array}$ & $\begin{array}{l}-0.0906 \\
(0.0583)\end{array}$ & $\begin{array}{c}0.0014 \\
(0.1620)\end{array}$ & $\begin{array}{c}0.1070 \\
(0.1684)\end{array}$ \\
\hline Wanted fertility & & & & $\begin{array}{l}-0.1203^{*} \\
(0.0738)\end{array}$ & $\begin{array}{l}-0.1177 \\
(0.0994)\end{array}$ & $\begin{array}{c}-0.2188^{* *} \\
(0.0924)\end{array}$ \\
\hline Country fixed effects & No & Yes & Yes & No & Yes & Yes \\
\hline Decade fixed effects & No & No & Yes & No & No & Yes \\
\hline Number of observations & 203 & 203 & 203 & 203 & 203 & 203 \\
\hline Number of countries & 80 & 80 & 80 & 80 & 80 & 80 \\
\hline R-squared & 0.0084 & 0.8550 & 0.8616 & 0.0546 & 0.8590 & 0.8727 \\
\hline
\end{tabular}

Notes: Standard errors clustered by country are in parentheses. The symbols $*, * *$, and ${ }^{* *}$ imply that coefficients are statistically different from zero at 90, 95, and 99 percent confidence levels, respectively.

countries on different dates. There are 85 countries in total, but they appear in the sample in different frequencies and in years ranging from 1985 to $2013 .{ }^{14}$ We do not aim to provide a causal effect of modern contraceptive use on the fertility gap, instead we just provide an association between these variables.

Column (1) of Table 1 presents the estimated coefficients when we regress the fertility gap on the logarithm of per capita income and the percentage of women who have ever used modern contraceptive methods. As we can see, there is a negative association between unwanted fertility and the measure of modern contraceptive use, but this correlation is not statistically different from zero at the usual confidence levels. This negative correlation becomes statistically significant once we introduce country fixed effects, which control for time invariant effects such as legal origin, main religion, and other cultural factors. Country fixed effects substantially increase the explanation of the observed variation in the fertility gap. According to the specification in Column (2) the gap between realised and wanted fertility is significantly lower in countries where contraceptive use is more widespread. Column (3) regression contains the same explanatory variables as the one in Column (2) but we also introduce dummies for each decade. ${ }^{15}$ The correlation between the fertility gap and the percentage of women who have ever used modern contraceptive

\footnotetext{
${ }^{14}$ Some variables have missing observations and our final sample has 80 countries and 203 observations.

${ }^{15}$ We do not control for time dummies because some countries (19 in total) appear only once in the sample. We also do not control for the DHS phase fixed effects because few countries appear more than once in each phase. We observe only 5 cases in which a country appears more than once in a DHS phase.
} 
Table 2: Relationship between human capital attainment and fertility (unwanted and wanted) - Cross country analysis.

\begin{tabular}{|c|c|c|c|c|c|}
\hline & \multicolumn{5}{|c|}{ Dependent variable: Human capital attainment } \\
\hline & (1) & (2) & (3) & (4) & (5) \\
\hline Unwanted fertility & $\begin{array}{c}-1.1400^{* *} \\
(0.4516)\end{array}$ & $\begin{array}{c}-1.2715^{* * *} \\
(0.2058)\end{array}$ & $\begin{array}{c}-0.6264^{* * *} \\
(0.1878)\end{array}$ & $\begin{array}{c}-0.5891^{* * *} \\
(0.2216)\end{array}$ & $\begin{array}{c}-0.6078^{* * *} \\
(0.1904)\end{array}$ \\
\hline Wanted fertility & $\begin{array}{c}-1.3035^{* * *} \\
(0.1384)\end{array}$ & $\begin{array}{c}-1.1685^{* * *} \\
(0.1249)\end{array}$ & $\begin{array}{c}-0.5063^{* * *} \\
(0.1239)\end{array}$ & & $\begin{array}{c}-0.4897^{* * *} \\
(0.1219)\end{array}$ \\
\hline Log of per capita GDP & & & & $\begin{array}{c}0.4506 \\
(0.3323)\end{array}$ & $\begin{array}{c}0.3408 \\
(0.3233)\end{array}$ \\
\hline Country fixed effects & No & Yes & Yes & Yes & Yes \\
\hline Decade fixed effects & No & No & Yes & Yes & Yes \\
\hline Number of observations & 201 & 201 & 201 & 201 & 201 \\
\hline Number of countries & 71 & 71 & 71 & 71 & 71 \\
\hline R-squared & 0.5634 & 0.9752 & 0.9882 & 0.9864 & 0.9884 \\
\hline
\end{tabular}

Notes: Standard errors clustered by country are in parentheses. The symbols $*, * *$, and ${ }^{* *}$ imply that coefficients are statistically different from zero at 90, 95, and 99 percent confidence levels, respectively.

methods is weaker and not statistically different from zero at the usual confidence levels.

In Columns (4)-(6) of Table 1 we also add wanted fertility as an explanatory variable. The fertility gap decreases with wanted fertility, and the negative association between the fertility gap and the percentage of women who have ever used modern contraceptive methods becomes stronger. This correlation is statistically different from zero at a 99 percent confidence level once wanted fertility and country fixed effects are controlled in the regressions, which contradicts earlier results by Pritchett (1994). ${ }^{16}$ The most complete specification, which is our preferred one, explains about 87 percent of the observed variation in unwanted fertility.

Table 2 reports coefficients of regressions of human capital attainment, measured by the average years of schooling of the total adult population, on unwanted fertility for different specifications. ${ }^{17}$ In all regressions there exists a significant negative relationship between the fertility gap and educational attainment across countries. That is, when fertility is closer to its desired level, educational attainment is higher. This correlation is negative and significant even after including country fixed effects, decade dummies, and controlling for per capita income and wanted fertility. Unwanted and wanted fertility explain approximately 56 percent of the variation in education attainment in the sample, visible in Column (1). Educational attainment is also negatively correlated with wanted fertility,

\footnotetext{
${ }^{16}$ Clearly, our sample period is different from his, which might explain the difference.

${ }^{17}$ Missing observations in the human capital variable explain the difference in sample size between the regressions in Table 1 and Table 2.
} 
Table 3: Relationship between unwanted fertility and the use of modern contraceptive methods - Kenyan individual level data.

\begin{tabular}{|c|c|c|c|c|c|}
\hline & Depe & dent variab & : Unwanted $\mathrm{f}$ & rtility (fertili & gap) \\
\hline & (1) & (2) & (3) & (4) & (5) \\
\hline $\begin{array}{l}\text { Ever used modern contrac } \\
\text { methods }\end{array}$ & $\begin{array}{l}-0.5128^{* * *} \\
(0.1004)\end{array}$ & $\begin{array}{c}-0.2462^{* *} \\
(0.0975)\end{array}$ & $\begin{aligned}- & 0.05072^{* * *} \\
& (0.0962)\end{aligned}$ & $\begin{array}{c}-0.2185^{* *} \\
(0.0938)\end{array}$ & $\begin{array}{c}-0.1997^{*} \\
(0.1093)\end{array}$ \\
\hline Wanted fertility & & & $\begin{array}{c}-0.3917^{* * *} \\
(0.0254)\end{array}$ & $\begin{array}{c}-0.4851^{* * *} \\
(0.0240)\end{array}$ & $\begin{array}{c}-0.5159^{* * *} \\
(0.0263)\end{array}$ \\
\hline $\begin{array}{l}\text { Completed primary } \\
\text { education }\end{array}$ & & & & $\begin{array}{c}-0.2445^{* *} \\
(0.1041)\end{array}$ & $\begin{array}{c}-0.2833^{* *} \\
(0.1133)\end{array}$ \\
\hline $\begin{array}{l}\text { Completed secondary } \\
\text { education }\end{array}$ & & & & $\begin{array}{c}-1.8610^{* * *} \\
(0.1361)\end{array}$ & $\begin{array}{c}-1.3501^{* * *} \\
(0.1440)\end{array}$ \\
\hline $\begin{array}{l}\text { Completed higher } \\
\text { education }\end{array}$ & & & & $\begin{array}{c}-2.8633^{* * *} \\
(0.2066)\end{array}$ & $\begin{array}{c}-1.9356^{* * *} \\
(0.2124)\end{array}$ \\
\hline DHS phase dummies & No & Yes & Yes & Yes & Yes \\
\hline Other controls & No & No & No & No & Yes \\
\hline Number of observations & 4,205 & 4,205 & 4,203 & 4,203 & 3,430 \\
\hline R-squared & 0.0106 & 0.0728 & 0.1447 & 0.2222 & 0.2942 \\
\hline
\end{tabular}

Notes: Other controls include: Indicator for household wealth index in quintiles; Religion indicators, rural dummy and indicators for knowledge of contraceptive methods. Standard errors clustered by region of residence are in parentheses. The symbols ${ }^{*}, * *$, and ${ }^{* * *}$ imply that coefficients are statistically different from zero at 90, 95, and 99 percent confidence levels, respectively.

which reflects the quantity-quality trade-off. The negative association between unwanted fertility and human capital attainment will be one of the main endogenous mechanisms of how family planning interventions affect economic development in our theory.

\subsection{Micro-level Evidence from Kenya}

Using individual level data from five DHS surveys (1989, 1993, 1998, 2003, 2008-09) for Kenya, we also explore time and individual cross-sectional variations on how the use of modern contraceptives is associated with unwanted fertility at the household level. ${ }^{18}$

In Table 3 we regress the fertility gap of all 40 year or older women on the variable "ever use of modern contraceptives" and a set of other controls. As we can observe on Columns (1) to (5) in Table 3, there is a negative and statistically significant correlation between the ever use of modern contraceptives and the unwanted fertility for 40 year and older

\footnotetext{
${ }^{18}$ There is also the 2014 DHS Survey for Kenya, but observations on the variable "ever use of modern contraceptives" are missing.
} 
women in Kenya. In all regressions, the correlation is statistically different from zero at 90 percent confidence level. This is true even in our full specification, which includes controls for educational attainment (the dummy left out was the no education degree indicator), DHS phase fixed effects, indicators for the individual wealth quintile, religion dummies, rural dummy and indicators about knowledge of contraceptive methods. ${ }^{19}$ Notice also the negative relationship between educational attainment and the fertility gap. According to the full specification, women with a higher degree have on average 2 fewer unwanted children than women without an education degree..$^{20}$

Therefore what the reduced form evidence shows is that there might be a positive relationship between contraception use and education, via the reduction in the gap between actual and wanted fertility levels. This is a mechanism that we explore in our equilibrium model below to understand how family planning interventions affect individual decisions and aggregate outcomes.

\section{Model}

\subsection{Demographics and Endowments}

The economy consists of overlapping generations of individuals who live for three periods: childhood, young adulthood, and old adulthood. Children do not make any economic decisions and can acquire skills. Young adults are organised as couples and make the following economic choices: their desired number of children and the intensity of their contraceptive use. The number of pregnancies is stochastic, and the realised and desired number of pregnancies may be different. The use of contraception can lower the chances of an unwanted pregnancy. Once the number of pregnancies is realised, young couples may decide to abort some of them to close the fertility gap. Abortion is costly, both in terms of utility and in income. Young adults have one unit of productive time and are endowed with skills that they acquired during their childhood. They then invest their income into the education of their children, consume, and save. Old adults do not work and simply consume their savings.

\subsection{Production}

The consumption good is produced with a technology that uses capital, $K$, and efficiency units of labour, $L$, as inputs. The technology is represented by: ${ }^{21}$

$$
Y=A K^{\alpha} L^{1-\alpha}, \alpha \in(0,1), A>0 .
$$

\footnotetext{
${ }^{19}$ In Subsection A.2 of the companion Online Appendix (Tables A6 and A7), we show that the results of Table 3 are also robust conditional on whether or not the husband wants more children than the woman.

${ }^{20}$ Ideally we would regress the education attainment of the offspring on her mother's unwanted fertility. However, this is not available in the DHS.

${ }^{21}$ In order to simplify the notation we will abstract from the subscript $t$ to denote the time period and use the convention that object' stands for future variables.
} 
Capital depreciates fully after use.

Let $w$ be the wage rate and let $R$ be the rental price of capital. Profit maximisation implies that input prices are paid according to their marginal productivity, such that:

$$
\begin{aligned}
& w=(1-\alpha) A K^{\alpha} L^{-\alpha}, \\
& R=\alpha A K^{\alpha-1} L^{1-\alpha} .
\end{aligned}
$$

\subsection{Households}

Desired and realised fertility: Young couples first decide on the number of children that they want to have, $\tilde{n} .^{22}$ Then, the number of pregnancies, $p$, is realised. We assume that

$$
p-\tilde{n}=\max \{\eta-\theta q, 0\},
$$

where $q \geq$ is the investment in contraception, $\eta$ is a random variable with distribution $\Gamma(\eta)$ and support $[0, N]$, and $\theta$ is a positive parameter. ${ }^{23}$ We are not saying that without modern contraceptive methods families could not use traditional practices to control fertility (e.g., extended breast-feeding and sexual abstinence). Equation (4) simply implies that the use of modern contraceptive methods can decrease the fertility gap relative to a situation without these birth control (supply) technologies.

Contraception is costly and the relative price of contraception is $\phi_{q}$. This includes not only the price to buy modern contraceptives on pharmacies or to acquire (including transportation costs) them in public clinics, but also the fact that they might be stocked out. Therefore, $\phi_{q}$ corresponds to supply factors which might affect the use of modern contraceptive methods. Contraception also generates a utility cost $\Psi_{q}>0$ whenever $q>0$. In some cultures, modern contraception use can be associated with promiscuity and women may also have the fear of side effects and adverse reactions related to, for instance, the use of pills. In addition, there may potentially be intra-household disagreement (husband versus wife desired fertility), which is not explicitly modelled here, about the use of contraceptives. For instance, Ashraf, Field, and Lee (2014) show that when women receive access to contraception alone they report lower subjective well-being than when they receive access to contraception with their husbands, suggesting a psychosocial cost. Therefore, the parameter $\Psi_{q}>0$ corresponds to demand barriers to the use of modern contraceptive methods. Once the number of pregnancies is realised, the household can choose to abort some of them, $a$, in order to close the gap between the number of realised pregnancies and the desired number of children. Abortion is costly both in terms of utility, such that there are disutility costs $\Psi_{a}>0$ whenever $a>0$, and in terms of the consumption good. The relative price of abortion is $\phi_{a}$. The realised number of children is:

$$
n=p-a .
$$

\footnotetext{
${ }^{22}$ Since adults are organised as couples, we can view $\tilde{n}$ as the desired number of children that each household wants to have. We abstract from intra-household bargaining over fertility. Doepke and Kindermann (2019) explore in detail the consequences of bargaining over fertility for a set of European countries.

${ }^{23}$ We could assume that instead of Equation (4), we have that $p-\tilde{n}=\eta-\theta q$. Then households could also have fewer pregnancies than the desired fertility. We focus on relatively poorer countries in which we find that on average there is a positive fertility gap for any level of parents' human capital.
} 
Investment in the use of modern contraceptives is an insurance against the risk of unwanted pregnancies. Abortion terminates a pregnancy with certainty. Therefore, we can see modern contraceptives as unwanted pregnancy preventives, while abortion is an ex post treatment (cf., Kremer and Syder, 2015). Both technologies incur costs and agents will take them into account when making their birth control choices.

Human capital: Parents invest in the education of their children, $e \geq 0$, such that the human capital of their children is equal to

$$
h^{\prime}=\epsilon \tilde{h}(e) .
$$

The function $\tilde{h}(e)$ is increasing, differentiable, and concave with respect to $e$, and the price of education in terms of the consumption good is $\lambda(e)$, which varies with $e$. We also assume that $\tilde{h}(0)>0$ such that the quality of children's income elasticity is increasing with income, as postulated by Becker (1960) and explored by Greenwood, Seshadri, and Vandenbroucke (2005), to generate the secular decline in fertility and the increase in human capital. The shock $\epsilon \sim F(\epsilon)$ has positive support and summarises unobserved factors that influence the human capital production process. Investment in education is in terms of the consumption good. Children are also time consuming. Each child takes a fraction $\chi \in(0,1)$ of her parents time endowment and $N \chi<1$.

Optimal decisions: Consumption of couples during the young adulthood period and old adulthood period are denoted by $c_{y}$ and $c_{0}^{\prime}$, respectively. Preferences of couples are represented by the following utility function:

$$
U\left(c_{y}, c_{0}^{\prime}, n, h^{\prime}\right),
$$

where $U(\cdot, \cdot, \cdot, \cdot)$ is differentiable, increasing, and concave in all arguments.

Let $s$ be the savings of a young adult couple and $\mathbf{I}_{a>0}$ be an indicator function which equals one when $a>0$ and zero otherwise. The problem of the couple with $p$ realised pregnancies who invested $q$ in contraception is to choose $c_{y}, c_{0}^{\prime}, a, s$, and $e$ to maximise

$$
\tilde{V}(h, p, q)=\max _{c_{y}, c_{0}^{\prime}, a, s, e \geq 0}\left\{E_{\epsilon}\left[U\left(c_{y}, c_{0}^{\prime}, n, \epsilon \tilde{h}(e)\right)\right]-\Psi_{a} \mathbf{I}_{a>0}\right\},
$$

subject to (5), (6),

$$
\begin{array}{r}
c_{y}+s+\phi_{q} q+\phi_{a} a+\lambda(e) e n=w h(1-\chi n), \\
c_{o}^{\prime}=R^{\prime} s .
\end{array}
$$

$E_{\epsilon}[\cdot]$ corresponds to expectations over $\epsilon$. Equation (9) corresponds to the budget constraint of the young couple. It implies that consumption plus savings of the household plus expenditures on contraception, abortion, and education must be equal to income. Budget constraint (10) states that in old adulthood, couples consume the principal and interest from their savings during the young adulthood period. 
Let $\mathbf{I}_{q>0}$ be an indicator function which equals one when $q>0$ and zero otherwise. The problem of a couple before the number of pregnancies is realised is to choose the number of desired children, $\tilde{n}$, and investment in contraception, $q$, in order to:

$$
V(h)=\max _{\tilde{n}, q \geq 0}\left\{E_{\eta}\left[\tilde{V}(h, b, q)-\Psi_{q} \mathbf{I}_{q>0}\right]\right\},
$$

subject to Equation (4). The notation $E_{\eta}[\cdot]$ denotes that expectations are taken over the stochastic number of pregnancies summarised by the random variable $\eta$.

\subsection{Equilibrium}

In a competitive equilibrium, agents and firms optimally solve their problems and all markets clear. Let $x=(h, \eta)$ with $x \in \mathcal{X}=(0, \infty) \times(0, N)$. The couples' optimal behaviour defines optimal policy functions $c_{y}(x), c_{o}^{\prime}(x), s(x), q(h), a(x), e(x)$, and $\tilde{n}(h)$. The stationary equilibrium in this economy is characterised by a stationary human capital distribution associated with the optimal behaviour of couples and firms. To characterise the stationary human capital distribution, first define the following function,

$$
\mathbf{1}\left(x, \epsilon, h^{\prime}\right)=\left\{\begin{array}{ll}
1 & \text { if } h^{\prime}=\epsilon \tilde{h}(e(x)) \\
0 & \text { otherwise }
\end{array} .\right.
$$

The function above takes the value of one if a child coming from parents with a state $x$ and a shock $\epsilon$ builds a human capital level $h^{\prime}$. It takes the value of zero otherwise. Next, construct a transition probability function,

$$
P\left(h^{\prime} \mid x\right)=\int \mathbf{1}\left(x, \epsilon, h^{\prime}\right) d F(\epsilon),
$$

which computes the probability that a child attains human capital level $h^{\prime}$ conditional on having parents with state $x$. The number of children of a household is given by

$$
n(x)=\tilde{n}(h)+\max \{\eta-\theta q(h), 0\}-a(x) .
$$

Based on this, define the distribution function of human capital as

$$
\mathrm{Y}\left(h^{\prime}\right)=\frac{\int_{\mathcal{X}} n(x) P\left(h^{\prime} \mid x\right) d \mathrm{Y}(h) d \Gamma(\eta)}{\int_{\mathcal{X}} n(x) d \mathrm{Y}(h) d \Gamma(\eta)} .
$$

The distribution of human capital in the economy is $Y$. The rate of population growth, $g$, in this economy is given by

$$
1+g=\int_{\mathcal{X}} n(x) d \mathrm{Y}(h) d \Gamma(\eta) .
$$

The law of motion for the distribution presented in Equation (12) takes into account population growth as evidenced by the normalisation in the denominator. In this economy both 
capital and labor will grow with the rate of population growth. To define the stationary equilibrium, one can de-trend these two variables in the following way,

$$
L=\frac{L_{t}}{(1+g)^{t}} \text {, and } K=\frac{K_{t}}{(1+g)^{t}} .
$$

Definition: (Stationary Competitive Equilibrium) A stationary competitive equilibrium for this economy consists of allocations for firms $\{K, L\}$, a collection of policy functions for households $\left\{c_{y}(x), c_{o}^{\prime}(x), s(x), q(h), a(x), e(x), \tilde{n}(h)\right\}$, a stationary distribution $\mathrm{Y}$, a vector of prices $\{w, R\}$, and a population growth rate $g$ such that:

i. Given the vector of prices $\{w, R\}$, the vector $\{K, L\}$ solves (2) and (3).

ii. Policy functions $q(h)$ and $\tilde{n}(h)$ solve value function $V(h)$ and

$$
p-\tilde{n}(h)=\max \{\eta-\theta q(h), 0\} .
$$

iii. Policy functions $\left\{c_{y}(x), c_{0}^{\prime}(x), s(x), a(x), e(x)\right\}$ solve value function $\tilde{V}(h, b, q)$.

iv. Market clearing conditions are such that:

$$
\begin{gathered}
\int_{\mathcal{X}}\left[c_{y}(x)+s(x)+\phi_{q} q(x)+\phi_{a} a(x)+\lambda(e) e(x) n(x)\right] d Y(h) d \Gamma(\eta) \\
+\frac{1}{1+g} \int_{\mathcal{X}} c_{o}(x) d Y(h) d \Gamma(\eta)=A K^{\alpha} L^{1-\alpha}, \\
L=\int_{\mathcal{X}} h(1-n(x) \chi) d Y(h) d \Gamma(\eta),
\end{gathered}
$$

and

$$
K^{\prime}=\int_{\mathcal{X}} s(x) d Y(h) d \Gamma(\eta) .
$$

v. The distribution of human capital $\mathrm{Y}$ solves (12).

vi. The population growth rate is given by (13).

\section{Fitting the Model to the Data}

In order to investigate the effects of family planning interventions on human capital dynamics, inequality, and income, we must assign values for the model parameters. We have prior information about some parameters but other parameters are specific to the analysis at hand and little is known about their magnitudes. Therefore, values for these parameters will be estimated such that the model matches key micro and macro moments of Kenya for the late 2000s, due to data restrictions. We use a minimum distance procedure 
which targets a set of data moments on wanted and unwanted fertility and family planning in terms of contraceptives and abortion conditional on education levels. These data moments are derived from the 2008 Kenya Demographic and Health Survey. Matching the cross-sectional distributions of fertility and family planning conditional on human capital ensures that the model delivers a credible link between fertility uncertainty, family planning instruments to mitigate it, and human capital accumulation. We concentrate on the following levels of education: 0 years of schooling, 4 years of schooling, 8 years of schooling, 12 years of schooling, and 16 years of schooling. We also target several aggregate moments such as income inequality, the consumption-output ratio, and the capital-output ratio, among others. First, however, we need to impose functional forms for some of the expressions of our theoretical framework. Below we describe in detail these functions and how we calibrate and estimate model parameters.

\subsection{Calibration and Estimation}

Model period: The model period is assumed to be 20 years. This is consistent with the 2008-2014 average life-expectancy in Kenya of around 60 years (cf., The World Bank, 2015).

Production technology: The capital share in income we get from the Penn World Tables (cf., Feenstra, Inklaar, and Timmer, 2015) and set it to $\alpha=0.36$. Capital depreciates fully after use. The productivity factor $A$ is chosen such that total output per capita is normalised to 1 . The production technology parameters are: $A$ and $\alpha=0.36$ (one to be estimated).

Fertility technology: The fertility shock $\eta$ has the following cumulative distribution function: $\Gamma(\eta)=\left(\frac{\eta}{N}\right)^{\kappa}$, where $N$ corresponds to the maximum number of unwanted pregnancies possible. We set the maximum number of unwanted pregnancies per woman to 10. In the grid for wanted fertility we also set the maximum number of wanted pregnancies to 10 so that a woman could have a maximum of 20 pregnancies in her lifetime. Since the model period is 20 years, this implies one pregnancy per year. The efficiency of contraception is determined by $\theta q$. Different combinations of parameters $\phi_{q}$ and $\theta$ lead to identical choices of consumption and fertility. In order to resolve this issue, we normalise the price of contraception to one such that $\phi_{q}=1$. The relative price of abortion is equal to $\phi_{a}>0$. The fertility technology parameters are: $N=10, \phi_{q}=1, \kappa, \theta$, and $\phi_{a}$ (three to be estimated).

Human capital function and child-rearing technology: The offsprings' human capital is given by $h^{\prime}=\epsilon \tilde{h}(e)$. We assume that $\tilde{h}(e)=h_{0}+h_{1} e^{\zeta}$. The fixed component $h_{0}$ implies non-homothetic preferences over human capital. This feature and the time cost of children, $\chi$, help us generate a negative relationship between fertility and parental income/education in the model. ${ }^{24}$ We restrict the choice of education to five discrete options: no education, four years, eight years, twelve years, and sixteen years. Each of these five discrete levels bears an education cost. The vector of education costs $\lambda(e) \in$ $\left\{0, \lambda_{1}, \lambda_{2}, \lambda_{3}, \lambda_{4}\right\}$ summarises the amount of consumption goods parents need to forgo in order to finance the education of a child to one of these five levels. The unobserved ability

\footnotetext{
${ }^{24}$ See Greenwood, Seshadri, and Vandenbroucke (2005) and Jones, Schoonbroodt, and Tertilt (2010).
} 
that augments the human capital production, $\epsilon$, is assumed to have a log-normal distribution with mean 0 such that $\ln \epsilon \sim N\left(0, \sigma_{\epsilon}^{2}\right)$. There is also the time cost of raising a child, $\chi$. The parameters for this section are: $\chi, h_{0}, h_{1}, \zeta, \lambda_{1}, \lambda_{2}, \lambda_{3}, \lambda_{4}$, and $\sigma_{\epsilon}^{2}$ (nine to be estimated).

Utility: Turning to preferences, the utility function takes the following functional form:

$$
U\left(c_{y}, c_{o}^{\prime}, n, \tilde{h}(e)\right)=\log \left(c_{y}\right)+\beta \log \left(c_{o}^{\prime}\right)+\gamma \log (n)+\xi \log (\tilde{h}(e)) .
$$

There are also two costs related to the household's taste: the disutility of contraception use and abortions. Recall that these were defined as $\Psi_{q} \mathbf{I}_{q>0}$ and $\Psi_{a} \mathbf{I}_{a>0}$ with $\Psi_{q}>0$ and $\Psi_{a}>$ 0 , where $\mathbf{I}_{q>0}$ and $\mathbf{I}_{a>0}$ are indicator functions when the use of modern contraceptives and abortion are positive, respectively. That is, households pay these costs if they engage in strictly positive use of each family planning option. Preference parameters are: $\beta, \gamma, \xi, \Psi_{q}$ and $\Psi_{a}$ (five to be estimated).

There are therefore 18 parameters of the model to be estimated via a minimum distance procedure. The parameters are set to match the normalisation of output per capita to one and the following 22 data moments:

(i) Realised fertility rate and unwanted fertility rate by levels of education. Note that matching these two series implies that the level of wanted fertility is matched too. Source: 2008 Kenya DHS. ${ }^{25}$ [8 targets]

(ii) Abortion rates and the fraction of women using modern contraception by levels of education. Source: 2008 Kenya DHS and own calculation based on Westoff (2008). ${ }^{26}$ [8 targets]

(iii) Fraction of people in each education category. Source: 2008 Kenya DHS. [3 targets]

(iv) Capital-output and consumption-output ratios. Source: Penn World Tables (cf., Feenstra, Inklaar, and Timmer, 2015) . [2 targets]

(v) Gini coefficient of household labor income. Source: The World Bank (2015). [1 target]

How do these data moments aid in the process of setting the model parameters? In a general equilibrium setup a change in any parameter affects all targets. However, some sets of data moments are more sensitive to certain parameters. The fertility and family planning targets ((i) and (ii)) conditional on human capital are useful in recovering preference parameters $\left\{\gamma, \zeta, \Psi_{q}, \Psi_{a}\right\}$ and the price of abortion $\phi_{a}$, as well as the fertility uncertainty $\{\kappa\}$, the efficiency of modern contraceptives $\theta$, and the time cost per child $\chi$. To be more

\footnotetext{
${ }^{25}$ In the model there are five levels of education: no schooling, 4 years of schooling, 8 years of schooling, 12 years of schooling, and 16 years of schooling. In the DHS survey there are four levels of education: No primary education, primary, secondary, and higher and more. Primary education in Kenya corresponds to 8 years of schooling. Therefore, in the map from the model to the data, we aggregate the no-education category and the 4-years-of-schooling category into one category - from 0 to 4 years of schooling.

${ }^{26}$ The total abortion rate is calculated using Equation (7) of Westoff (2008), which defines a statistical relation of the total abortion rate with the total fertility rate and the contraceptive prevalence rate. Subsection A1 of the Online Appendix shows precisely how the total abortion rate by education levels was calculated.
} 
precise, we explore the cross-sectional variation in abortion and contraception use to separately identify the preference parameters $\left(\Psi_{q}\right.$ and $\left.\Psi_{a}\right)$ and the technology parameters $(\theta$ and $\left.\phi_{a}\right)$. The idea is that preference and technology parameters will affect heterogenous households differently. The distribution over educational categories (iii) identifies the cost parameters $\left\{\lambda_{1}, \lambda_{2}, \lambda_{3}, \lambda_{4}\right\}$. The capital to output ratio helps to pin down the discount factor $\beta$. Matching aggregate targets (iv) along with targets on fertility, family planning, education, and inequality (v) help us in setting parameters for the human capital accumulation process $\left\{h_{0}, h_{1}, \sigma_{\epsilon}\right\}$.

Let $\Theta=\left\{\beta, \gamma, \xi, \Psi_{q}, \Psi_{a}, h_{0}, h_{1}, \zeta, \chi, \sigma_{\epsilon}, \kappa, \theta, \phi_{a}, \lambda_{1}, \lambda_{2}, \lambda_{3}, \lambda_{4}, A\right\}$ be the vector of parameters to be estimated, and define the difference between the model-generated 22 moments and the normalisation of output to one by $\mathcal{M}(\Theta)$, and the data moments $\mathcal{D}$ by $\mathbf{R}(\Theta)=\mathcal{D}-\mathcal{M}(\Theta)$. The minimum distance estimation amounts to choosing parameter values that minimize the squared form,

$$
\hat{\Theta}=\arg \min _{\Theta} \mathbf{R}(\Theta)^{\prime} \mathbf{W} \mathbf{R}(\Theta),
$$

where $\mathbf{W}$ is a diagonal weighting matrix. We use an identity matrix in our base estimation. Table 4 reports the calibrated and estimated parameter values that result from the baseline estimation procedure above for Kenya.

Here are some comments on the estimated parameters. Since the model period corresponds to 20 years, then a discount factor of $\beta=0.5952$ implies that agents discount the future at a real rate of 2.6 percent per year. Given the cost of each education level, we can observe that the utility weight on the quality of children is higher than the utility weight on the quantity of children. In addition, the utility cost of contraception is much smaller than the utility cost of abortions. Also, given that the maximum number of unwanted pregnancies is 10 , the relative price of contraception is equal to one, and $\theta=347.5306$, then with less than 3 percent of GDP it is possible to avoid any unwanted pregnancies in the model. The time cost per child is about 3.5 percent, which is roughly half the value calibrated by de la Croix and Doepke (2003). However, de la Croix and Doepke (2003) calibrated this parameter for the United States economy, while our baseline economy is Kenya; we should expect this time cost to be smaller for developing economies than for the United States. Finally, the human capital accumulation function features a large fixed component, $h_{0}=4.6612$, which helps in generating the quantity-quality trade-off observed in the data.

\subsection{Model Fit}

Now, we discuss the fit of the model with respect to targeted and some non-targeted moments. Table 5 reports these moments in the data and in the model.

The model matches the fraction of adults in each education category very well, as seen in Figure $1 .{ }^{27}$ Interestingly, when we run a Mincerian regression with the model generated data to calculate the average returns to one additional year of schooling, we show that one additional year of schooling increases on average income by 8.1 percent. Schoellman

\footnotetext{
${ }^{27}$ The average years of schooling in the model is 7.68 years, while it is 7.83 in Kenya.
} 
Table 4: Calibrated and estimated parameters

\begin{tabular}{llrl}
\hline \hline Parameter & Description & Value & Comment \\
\hline \hline Calibrated parameters (3 parameters) & & \\
\hline$\alpha$ & Capital share in income & 0.36 & Feenstra et al (2015) \\
$N$ & Max. number of unwanted pregnancies & 10 & Normalised \\
$\phi_{q}$ & Price of modern contraceptives & 1 & Normalised \\
\hline \hline Estimated parameters (18 parameters) & & \\
\hline$A$ & TFP parameter & 0.6602 & Moments (i)-(v) \\
$\beta$ & Discount factor & 0.5952 & Moments (i)-(v) \\
$\gamma$ & Utility weight on fertility & 0.8819 & Moments (i)-(v) \\
$\zeta$ & Utility weight on human capital & 1.9252 & Moments (i)-(v) \\
$\Psi_{q}$ & Utility cost of contraception & 0.0024 & Moments (i)-(v) \\
$\Psi_{a}$ & Utility cost of abortion & 0.0804 & Moments (i)-(v) \\
$h_{0}$ & Human capital - fixed & 4.6612 & Moments (i)-(v) \\
$h_{1}$ & Human capital - marginal & 0.0349 & Moments (i)-(v) \\
$\zeta$ & Human capital - curvature & 2.1145 & Moments (i)-(v) \\
$\chi$ & Time cost per child & 0.0353 & Moments (i)-(v) \\
$\sigma_{\epsilon}$ & Std of ability shock & 0.5992 & Moments (i)-(v) \\
$\kappa$ & Fertility uncertainty & 0.2830 & Moments (i)-(v) \\
$\theta$ & Efficiency of contraception & 347.5306 & Moments (i)-(v) \\
$\phi_{a}$ & Abortion cost & 0.0033 & Moments (i)-(v) \\
$\lambda_{1}$ & Education cost: 4 years of schooling & 0.0047 & Moments (i)-(v) \\
$\lambda_{2}$ & Education cost: 8 years of schooling & 0.0093 & Moments (i)-(v) \\
$\lambda_{3}$ & Education cost: 12 years of schooling & 0.0646 & Moments (i)-(v) \\
$\lambda_{4}$ & Education cost: 16 years of schooling & 0.2392 & Moments (i)-(v) \\
\hline \hline
\end{tabular}

(2012) estimated the returns to schooling in Kenya to be equal to 8.3 percent. Therefore, our model produces an average returns to schooling very close to the one observed in the data. Consequently our model is consistent on how human capital maps onto income, which is one of our key mechanisms of how family planning interventions might affect individual outcomes. The model does also a good job in reproducing the pattern of modern contraceptives prevalence and the total fertility rate conditional on the level of human capital observed in the data. ${ }^{28}$ (See Figures 2(a) and 2(c).) Therefore, the model replicates qualitatively and quantitatively the trade-off between child quantity and quality which is present in the empirical evidence. The model does generate, however, a lower number of abortions than in the data for the lower tail and upper tail of the abortion distribution conditional on the level of education, but observed abortions in the middle of this distribution match well. (See Figure 2(b).) Regarding unwanted fertility, the model overestimates by 30 percent this measure for adults with no primary education and underestimates by 50 percent this measure for adults with a primary education degree. (See Figure 2(d).) Since

\footnotetext{
${ }^{28}$ The model overestimates the fertility rate at the very top of the human capital distribution.
} 
Table 5: Facts, Data versus Model

\begin{tabular}{lcc}
\hline \hline & \multicolumn{2}{c}{ Kenya, 2008 } \\
Statistics & Data & Model \\
\hline \hline Targeted moments & & \\
\hline Adults with no primary education (\%) & 0.162 & 0.1699 \\
Adults with 8 years of schooling (\%) & 0.604 & 0.6230 \\
Adults with 12 years of schooling (\%) & 0.181 & 0.1571 \\
Adults with 16 years of schooling (\%) & 0.053 & 0.0511 \\
Fertility, parents with no primary education & 6.7 & 6.3675 \\
Fertility, parents with 8 years of schooling & 5.5 & 5.5864 \\
Fertility, parents with 12 years of schooling & 4.9 & 4.9087 \\
Fertility, parents with 16 years of schooling & 3.1 & 4.2051 \\
Unwanted fertility, parents with no primary education & 0.9 & 1.1761 \\
Unwanted fertility, parents with 8 years of schooling & 1.8 & 0.9079 \\
Unwanted fertility, parents with 12 years of schooling & 1.3 & 0.7928 \\
Unwanted fertility, parents with 16 years of schooling & 0.6 & 0.5784 \\
Abortions, parents with no primary education & 1.06 & 0.8118 \\
Abortions, parents with 8 years of schooling & 0.68 & 0.7366 \\
Abortions, parents with 12 years of schooling & 0.65 & 0.6559 \\
Abortions, parents with 16 years of schooling & 0.97 & 0.6479 \\
Modern contraceptive prevalence, parents with no primary education & 0.12 & 0.1190 \\
Modern contraceptive prevalence, parents with 8 years of schooling & 0.348 & 0.3353 \\
Modern contraceptive prevalence, parents with 12 years of schooling & 0.418 & 0.4439 \\
Modern contraceptive prevalence, parents with 16 years of schooling & 0.521 & 0.5561 \\
Income Gini & 0.485 & 0.4788 \\
Capital-to-output ratio, K/Y & 1.57 & 1.3079 \\
Consumption-to-output ratio, C /Y & 0.7118 & 0.6644 \\
Normalisation of output per capita to one & 1 & 1.051 \\
\hline \hline Non-targeted moments & & \\
\hline Average returns to schooling & 8.3 \\
Unit abortion cost, \% of GDP per capita & 8.1 \\
Contraception expenditure, \% of GDP per capita & 0.68 & 0.063 \\
\hline \hline & & \\
\hline
\end{tabular}




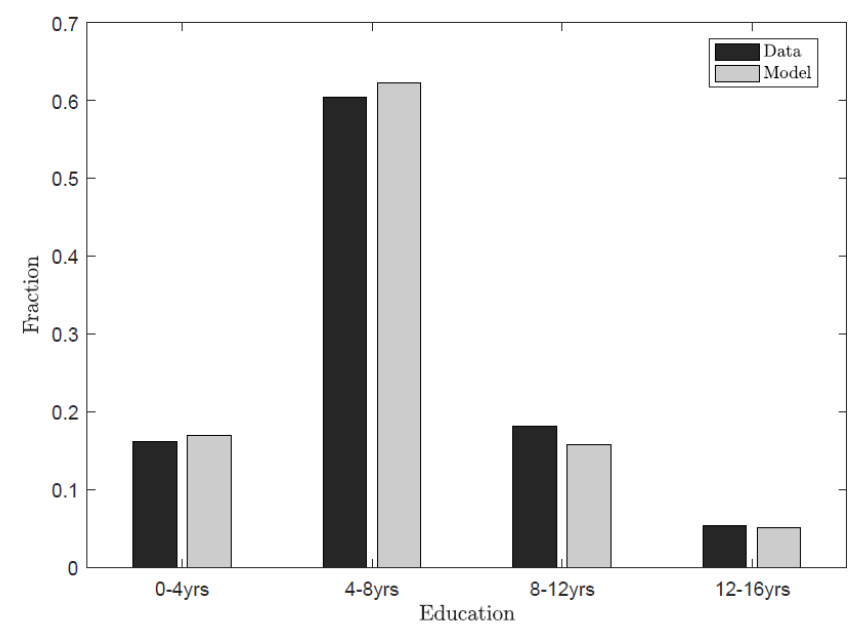

Figure 1: Data versus model - Fraction of adults by education. Source: 2008 Kenya DHS.

the fraction of adults with primary education is about 3.7 larger than the fraction of adults with no primary education, then if anything, the model underestimates the level of unwanted fertility. In fact, the overall gap between realised and wanted fertility is about 1.2 children for Kenya in 2008, while in the model this gap is 0.9185. In the Online Appendix we also fit the model to moments from Ghana (Subsection D.3) and the fit is better when considering abortion and unwanted fertility by education. Our main conclusions derived from our quantitative analysis for Kenya are robust to the case of the model fit to Ghana.

Regarding the aggregate measures, the model replicates fairly well the Gini index of income and is close to reproducing the capital-to-output ratio and the consumption-tooutput ratio observed in the data. For the non-targeted statistics, the model underestimates slightly the aggregate level of unwanted fertility. There are other factors affecting unwanted fertility, such as infant mortality risks, which are not explicitly modelled in our framework. However, given that we underestimate unwanted fertility, we should see the effects of non-targeted family planning interventions on fertility and other outcomes as lower bounds. ${ }^{29}$ Finally, the abortion $\operatorname{cost}^{30}$ as a fraction of per capita income generated in the model is in the lower range of what is observed in the data. Therefore, it does not seem

\footnotetext{
${ }^{29}$ We underestimate total expenditures on modern contraceptive methods as a share of per capita GDP by at least half of what is observed in the data. We calculate expenditures on modern contraceptives in Kenya by using the proportion of adults adopting each method, and the commodity cost plus personal costs (ex., nurses and doctors) per couple year of protection of each method (cf., USAID, 2010). This gives a weighted average of US\$6.41 per year of protection or 0.68 percent of the Kenyan GDP per capita in 2008.

${ }^{30}$ Abortion in Kenya is permitted only when the life or health of the woman is in danger. Yet unsafe abortion remains a leading cause of maternal morbidity and mortality in Kenya (cf., Mohamed, Izugbara, Moore, Mutua, Kimani-Murage, Ziraba, Bankole, Singh, and Egesa, 2015). The price of abortion in Kenya ranges from US\$30-65, in illegal clinics and international charity Marie Stopes clinics (cf., Fisher, 2016; Hussain, 2012; Migiro, 2011; Robbins, 2013), to about US\$200. Since a woman would abort on average one child in her lifetime, then the effective unit cost of abortion in the model is in the range of what is observed in the data.
} 


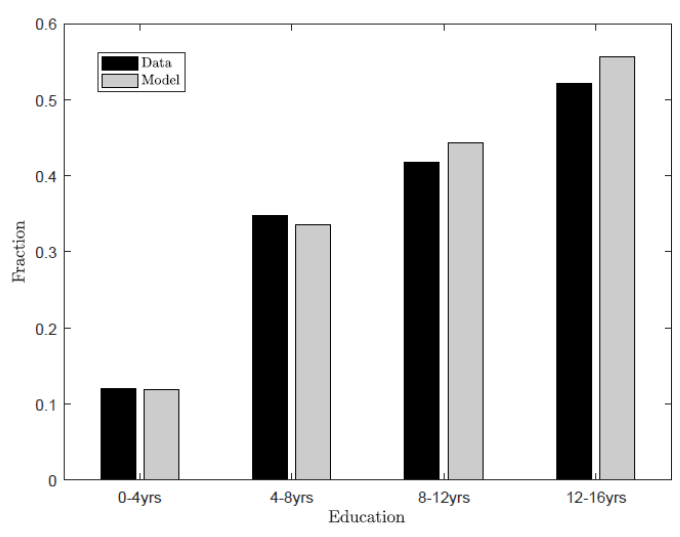

(a) Contraceptive prevalence by education

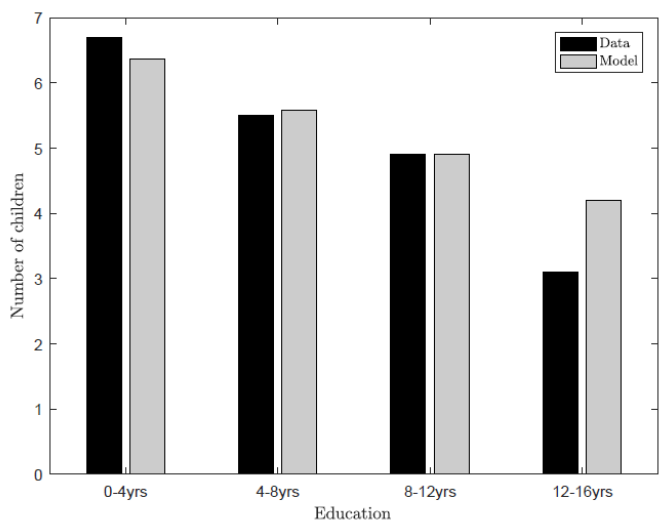

(c) Fertility by education

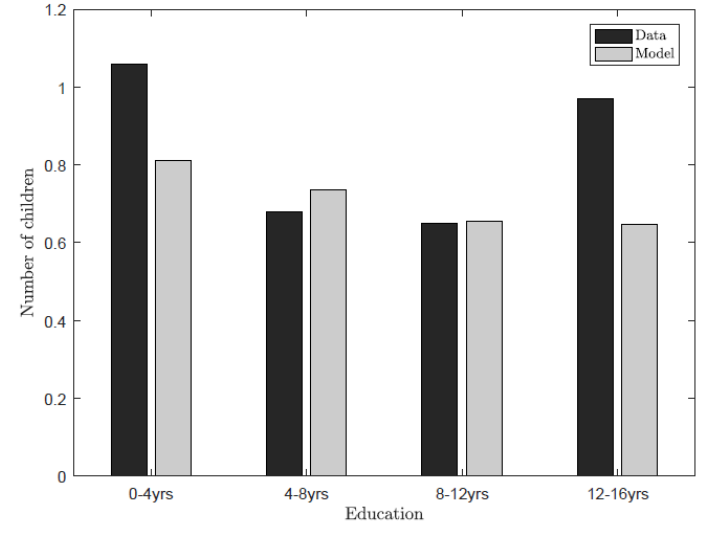

(b) Abortions by education

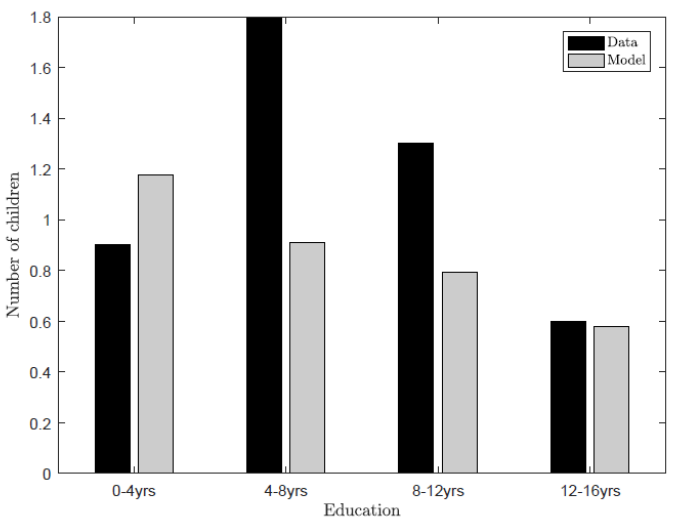

(d) Unwanted fertility by education

Figure 2: Data versus model - Selected statistics. Source: 2008 Kenya DHS.

that we are overestimating the values for the cost of modern contraceptives and abortion and therefore making them artificially important in our quantitative simulations on how family planning policy affects fertility, and aggregate outcomes.

\subsection{Family Planning Interventions and Fertility: Model versus Data}

Before we implement family planning interventions in our baseline model, we summarise the findings of key studies of the empirical literature, which recover the causal estimates of the effects of family planning policies on fertility and other individual outcomes. This is important in order to provide confidence that our family planning interventions do not overestimate their impacts on fertility, and therefore on aggregate variables. These interventions include subsidising the price of modern contraceptives, and programs to change male attitudes toward family planning. Table 6 summarises five studies and Miller and Babiarz (2016) provide a comprehensive overview of the empirical evidence. 


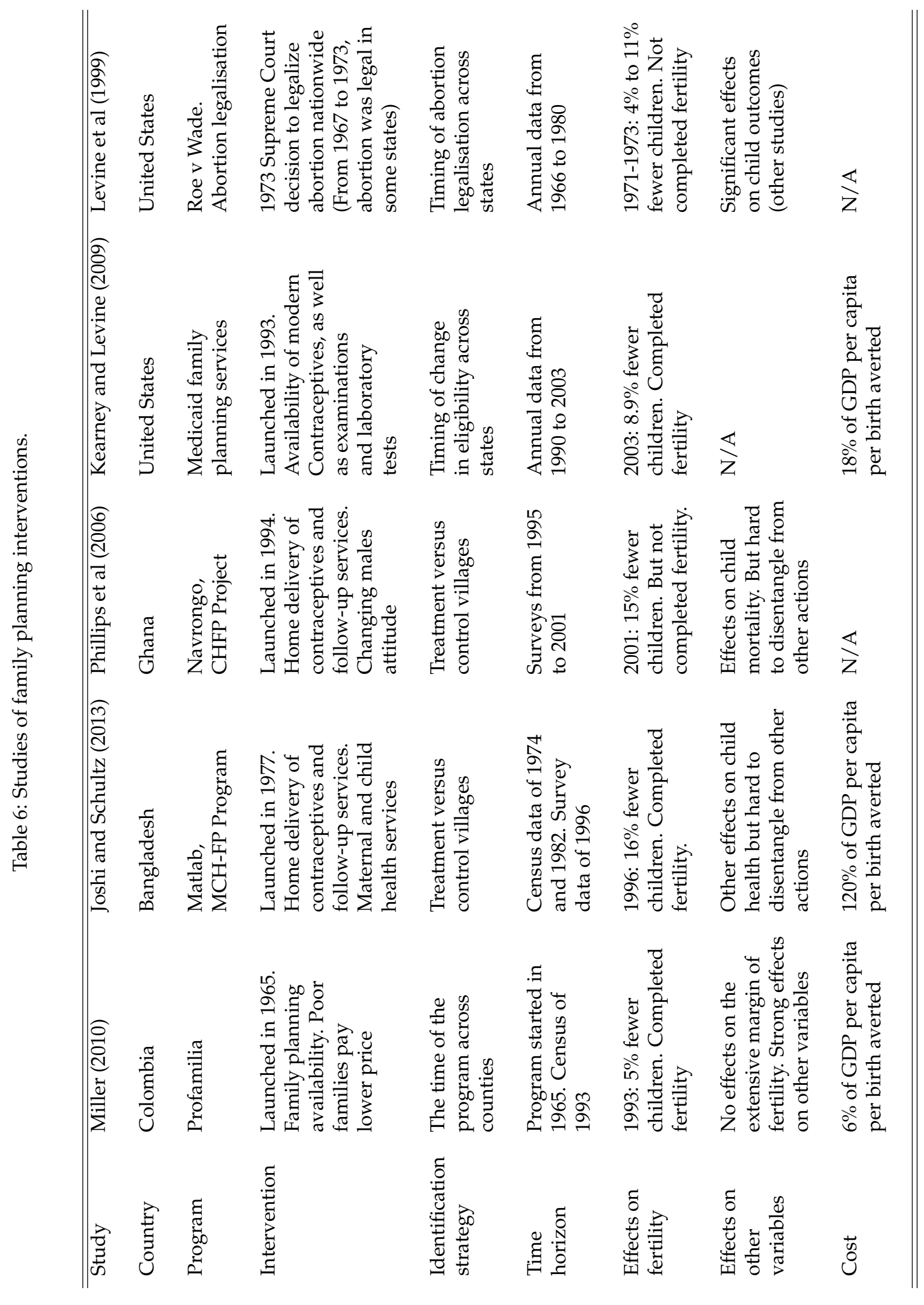


The first study evaluates the impact of Profamilia, a large family planning program in Colombia. This program was founded in 1965 in Bogota and then it was spread to other cities in the country. Profamilia is considered a successful program in providing modern contraceptives at subsidised rates for poor women in urban and rural areas. The time of the launching of the program varied across counties, and this provides the source of variation that Miller (2010) explores to show that Profamilia reduced in 5 percent the fertility of women in their lifetime (about one-third of a child) in Colombia. According to Miller (2010) this program costs about 6 percent of per capita GDP per birth averted.

Another famous family planning intervention is the 1977 Maternal and Child Health and Family Planning (MCH-FP) program in the Matlab region in Bangladesh. The $\mathrm{MCH}-$ FP program had home delivery of modern contraceptives, follow-up services, and general advices to poor women in treatment villages. Maternal and child health services were added over time. Joshi and Schultz (2013) show that the program in 1996 reduced completed fertility by 16 percent ( 0.78 of a child) in treatment villages when compared to control villages. The program has been criticised by its unrealistic cost since the cost per birth averted of the program was about 120 percent of per capita GDP. However, because the program offered a combination of family planning, maternal and child health interventions, then it is not possible to attribute the effects of the program to one of its actions, and to disentangle the cost-benefit of each component. Therefore, it is hard to compare both the effects and the costs of the type of family planning interventions we are able to implement in our theoretical framework with those from the MCH-FP program.

The Navrongo randomised control trial experiment in Ghana was based on the Matlab experiment in Bangladesh. It was launched in 1993 and the treatment arms combined family planning services with a variety of maternal and child health services. After five years, the reduction in completed fertility associated with the program was about 15 percent among married women (cf., Phillips, Bawah, and Binka, 2006). However, such effects on fertility have declined over time. ${ }^{31}$ For reasons similar to those associated with the Matlab project, it is not straightforward to compare the effects on fertility of this program with those generated by our theoretical framework.

Kearney and Levine (2009) use state and temporal variation in the change in access (eligibility based on income) to family planning services in the United States through Medicaid to identify the causal effects of access to such services on fertility. They report an 8.9 percent reduction in completed fertility, and a cost of birth averted of about 18 percent of per capita GDP. ${ }^{32}$ Bailey, Malkova, and McLaren (2017) using similar identification strategy, find that children from families exposed to such programs had 2.8 percent higher household incomes and were also 7 percent less likely to live in poverty. Therefore, even in developed countries such as the United States, it seems that supply-side family planning interventions can have sizeable effects on fertility and children's outcome.

\footnotetext{
${ }^{31}$ See Phillips, Jackson, Bawah, MacLeod, Adongo, Baynes, and Williams (2012).

${ }^{32}$ Using a back-of-the-envelope calculation, they estimate a total cost of US\$6,800 per birth averted in 2001. Then using the 2001 GDP per capita in the United States, the cost as fraction of income per capita is 18 percent. As they argue, this is probably an upper bound measure, since the cost of expanding the system was calculated by using the average cost of the program, and not the marginal cost of the existing program.
} 
When we improve access to modern contraceptives (decreasing the price $\phi_{q}$ ) in our model, we show that such supply-side intervention generates a reduction in fertility of 6.86-8.3 percent, ${ }^{33}$ which are consistent with the estimates reported in empirical literature (see Table 6). The cost per birth averted is 7.21 percent of per capita GDP when general equilibrium effects are considered, and 5.97 percent when they are not. Those numbers are very close to those reported by Miller (2010), which evaluates a type of family planning intervention that is close in nature to the one implemented in our counterfactual exercises.

Improving access to abortion in our model would also generate a reduction in fertility similar to those found in the empirical literature. When general equilibrium effects are taken into account, improvements in access to abortion reduce fertility in 5.23 percent (see Table 8). When price effects are not considered, then the reduction in fertility is roughly 5.41 percent. Such numbers are close to the estimated effects of legalising abortion on fertility in the United States (cf., Levine, Staiger, Kane, and Zimmerman, 1999).

Therefore, the effects of family planning policies on fertility in our model are consistent with the microeconometric literature on family planning and fertility. This gives us confidence in our quantitative exercises, which are presented in the next section.

\section{Quantitative Analysis}

With all parameters calibrated and estimated we can now explore how the equilibrium properties of the model change with different family planning policies. ${ }^{34}$ Fertility is known to be an important determinant of individual and aggregate outcomes, but little is known about the aggregate and distributional effects of family planning policies.

\subsection{Extreme Scenarios}

Table 7 reports key statistics of two extreme counterfactual experiments. (See also Figure 3.) In the first (No fertility shocks) experiment we consider an economy in which households can perfectly control family size such that we set the number of unwanted pregnancies exogenously to zero, $N=0$. There is no uncertainty in fertility and therefore no need to use modern contraceptives $(q=0)$ or rely on abortion $(a=0)$ to control reproduction. The theoretical framework boils down to a standard quantity-quality fertility model of economic growth. Unwanted fertility goes down to 0 and the average fertility goes down by about 0.4 of a child, i.e., total fertility is reduced by about 7 percent. ${ }^{35}$ This last result confirms that aggregate fertility is quite unresponsive to changes in contraceptive access and that the cross-country differences in fertility are mostly driven by the desired family size (cf., Pritchett, 1994) and social norms (cf., de Silva and Tenreyro, 2019).

\footnotetext{
${ }^{33}$ Details of such intervention and others are found in Subsection 6.2.

${ }^{34}$ We also implement sensitivity analysis with respect to the 18 internally calibrated parameters, including how the results of two counterfactual exercises are affected by local changes in each of these parameters. See the Online Appendix C.

${ }^{35}$ May (2012) reports that family planning interventions in different countries reduced lifetime fertility between 0.5 and 1.5 children per woman, and most estimates point to the lower end of this interval.
} 
The aggregate fertility measure hides important compositional differences. In this counterfactual experiment the share of households without a primary education falls by 42 percent relative to the baseline. Figure 3(b) shows that fertility decreases for all education levels except for the highest level (16 years of schooling). For this group fertility increases because there are fewer resources spent on contraceptives and abortions, and agents can target a higher wanted fertility (income effect) since there is no risk of having unwanted pregnancies. Investment in human capital and in physical capital rise relative to the baseline. The average number of years of schooling increases by one year, ${ }^{36}$ and the stock of physical capital increases by 20 percent relative to the benchmark case. ${ }^{37}$ Such movements in inputs in production increase the real wage rate by 4 percent, decrease the interest rate by 7 percent, and increase output per capita by 13 percent relative to the baseline. Inequality decreases and most of this reduction is concentrated at the bottom of the income distribution. The ratio for the 90th and 50th percentiles of income remains roughly constant, but the ratio for the 90th and 10th percentiles of income decreases by about 13 percent relative to the baseline. Although welfare is difficult to measure in an economy with endogenous fertility, as explained in Golosov, Jones, and Tertilt (2007), ${ }^{38}$ we still report the average welfare for the benchmark economy in each experiment. Welfare is measured simply in utils, which implies that only an ordinal comparison can be inferred. A compensate variation could clearly be reported, but given the problems to compare welfare in this setting we decide to not report this variation or focus on the welfare analysis.

In order to assess the main channels driving our results, we investigate the effects of shutting down general equilibrium effects (partial equilibrium), the wanted fertility (exogenous fertility) channel, and the education channel (exogenous education). By fixing the interest rate at the baseline level we are considering a small open economy in which not only the real interest rate is exogenously determined, but also (given the constant returns to scale production function) the real wage rate. We observe that relative to the baseline the overall results are quite similar to the case of the full counterfactual experiment in which fertility is perfectly controlled and general equilibrium movements, which lead to changes in the capital effective labor ratio, do not seem to drive the overall results.

In the second decomposition exercise (exogenous fertility) we impose the decision rules for desired fertility from the baseline economy into the economy with no fertility shocks. Notice that while households can target a higher wanted fertility rate than in the baseline when fertility is perfectly controlled, in this counterfactual exercise we shut down this effect. The average fertility falls by about one child (instead of 0.4 of a child) relative to the baseline, which is similar to the decrease in unwanted fertility. Now, with artificially lower fertility, families can invest even more in physical and human capital than when wanted fertility is also endogenous. The average number of years of schooling of the adult population increases by 1.5 years and physical capital increases by 68 percent

\footnotetext{
${ }^{36}$ This is mainly due to the decrease in the share of adults with no primary education, which decreases by 10 percentage points. See Figure 3(a).

${ }^{37}$ De Magalhães and Santaeulàlia-Llopis (2018) show that even in Sub-Saharan Africa, which is poorer than Kenya, the wealth to income ratio grows over the life-cycle.

${ }^{38}$ We do not have a dynastic structure and it is hard to compute the welfare of those who are not born.
} 
Table 7: Counterfactual experiments: Extreme cases, Kenya 2008

\begin{tabular}{|c|c|c|c|c|c|c|c|c|c|}
\hline \multirow{3}{*}{ Statistics } & \multirow{3}{*}{ Baseline } & \multicolumn{8}{|c|}{ Counterfactuals } \\
\hline & & \multicolumn{4}{|c|}{ No fertility shocks } & \multicolumn{4}{|c|}{ No family planning } \\
\hline & & $\begin{array}{l}\text { Full } \\
\text { exp. }\end{array}$ & $\begin{array}{c}\text { Partial } \\
\text { equil }\end{array}$ & $\begin{array}{l}\text { Exog. } \\
\text { fert. }\end{array}$ & $\begin{array}{l}\text { Exog. } \\
\text { educ. }\end{array}$ & $\begin{array}{l}\text { Full } \\
\text { exp. }\end{array}$ & $\begin{array}{c}\text { Partial } \\
\text { equil. }\end{array}$ & $\begin{array}{l}\text { Exog. } \\
\text { fert. }\end{array}$ & $\begin{array}{l}\text { Exog. } \\
\text { educ. }\end{array}$ \\
\hline \multicolumn{10}{|l|}{ Output, input and prices } \\
\hline$Y_{p c}^{i} / Y_{p c}^{b a s e l}$ & 1 & 1.13 & 1.12 & 1.31 & 1.13 & 0.86 & 0.88 & 0.74 & 1.11 \\
\hline$K^{i} / K^{\text {basel }}$ & 1 & 1.21 & 1.18 & 1.68 & 1.21 & 0.81 & 0.84 & 0.61 & 1.21 \\
\hline Schooling (years) & 7.68 & 8.78 & 8.75 & 9.07 & 8.78 & 6.61 & 6.72 & 6.16 & 7.93 \\
\hline$w^{i} / w^{\text {basel }}$ & 1 & 1.04 & 1 & 1.15 & 1.04 & 0.96 & 1 & 0.89 & 1.05 \\
\hline$r^{i} / r^{\text {basel }}$ & 1 & 0.93 & 1 & 0.78 & 0.93 & 1.07 & 1 & 1.21 & 0.92 \\
\hline \multicolumn{10}{|l|}{ Fertility and family planning } \\
\hline Av. fertility & 5.54 & 5.16 & 5.08 & 4.50 & 5.16 & 6.07 & 6.10 & 6.88 & 5.05 \\
\hline Av. unw. fert. & 0.92 & 0 & 0 & 0 & 0 & 2.12 & 2.12 & 2.12 & 2.12 \\
\hline Contrac. use (\% HHs) & 33 & 0 & 0 & 0 & 0 & 0 & 0 & 0 & 0 \\
\hline Pregn. aborted (\%) & 12 & 0 & 0 & 0 & 0 & 0 & 0 & 0 & 0 \\
\hline Av. contrac. exp./wh (\%) & 0.28 & 0 & 0 & 0 & 0 & 0 & 0 & 0 & 0 \\
\hline \multicolumn{10}{|l|}{ Inequality and welfare } \\
\hline Gini index & 0.48 & 0.47 & 0.47 & 0.47 & 0.47 & 0.47 & 0.48 & 0.47 & 0.48 \\
\hline Labour inc $90 / 50$ & 3.83 & 3.89 & 3.88 & 4.05 & 3.89 & 3.56 & 3.69 & 3.44 & 3.44 \\
\hline Labour inc $90 / 10$ & 12.57 & 10.89 & 10.88 & 10.63 & 10.89 & 10.96 & 10.93 & 9.82 & 12.04 \\
\hline Welfare & 3.86 & 4.11 & 4.07 & 4.25 & 4.11 & 3.65 & 3.70 & 3.49 & $-\infty$ \\
\hline
\end{tabular}

relative to the baseline. Consequently, output per capita increases by 31 percent instead of 13 percent. Therefore, understanding how targeted fertility decisions change with family planning interventions is important to assess the full impact of these policies on individual and aggregate outcomes. In the final decomposition, we keep the policy function of education as in the baseline and let all other margins be adjusted. We observe that relative to the baseline, aggregate and distributional results are in equilibrium similar to when all channels are effective, which suggests that endogenous changes in investment in education do not seem to be driving the economic effects of family planning interventions.

The second extreme case corresponds to the situation in which there is no possibility to control family size unless households change wanted fertility. In order to implement this experiment in our model we simply need to make the utility cost of modern contraceptives and abortions to be so large that it is never optimal for households to use one of those two methods to control their fertility. Relative to the baseline, the average fertility increases by 0.54 of a child, while unwanted fertility increases from 0.92 to 2.12. Consequently, wanted fertility is clearly adjusted downward. Households invest less in human and physical capital and output decreases by 14 percent. Therefore, the difference in output per capita between an economy without any modern control of fertility to another in which there is perfect control of family size is of about 30 percent. In the model without access to modern contraceptives or abortion there is lower inequality relative to the benchmark case, which is due mostly to the reduction of the share of agents acquiring skills. The share of households in all education categories decreases with the only exception being for the share of 


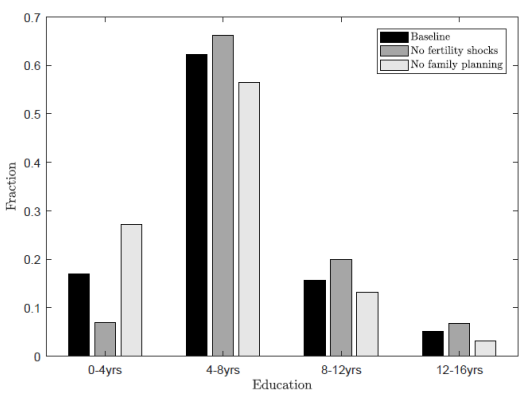

(a) Fraction of adults by education

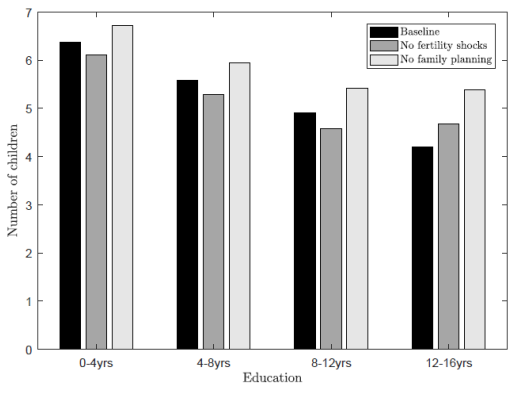

(b) Fertility by education

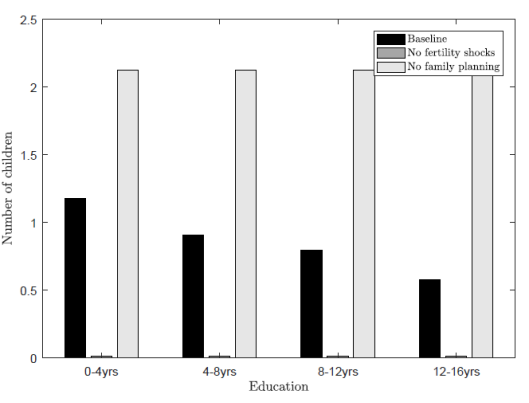

(c) Unwanted fertility by education

Figure 3: Counterfactual experiments: Extreme cases and baseline.

households without a primary degree, which increases by 60 percent. We also provide a decomposition of the full effect by shutting down different channels. As before, general equilibrium effects do not seem to be an important channel, since the model with fixed input prices yields similar results to the baseline. By assuming that the wanted fertility is unchanged, we notice that output would decrease even more than in the full experiment. This is rather intuitive since wanted fertility decreases when modern contraceptives and abortion are not available. Interestingly, output would rise if we keep the education policy unchanged. This is because fertility is lower and investment in education is higher in the benchmark than in the case without fertility control. When the education policy function is kept as in the baseline, households will decrease wanted fertility even more than in the full experiment and will also increase savings. Therefore, relative to the baseline, average years of schooling and physical capital would increase, as well as per capita output.

The following conclusions emerge from these extreme experiments and their decomposition: (i), although reproductive behaviour is mainly driven by demand as suggested by many economists (cf., Becker, 1960; Pritchett, 1994), access to modern contraceptives and abortions indeed shape the distributional pattern of fertility and consequently human capital dynamics and savings of a society; (ii), family planning interventions can have sizeable effects on per capita income and seem to improve welfare, in particular of those households at the lower tail of the income distribution in a developing country like Kenya; and (iii), there is clearly an upper bound limit on how family planning policy can affect aggregate outcomes. This is mostly shown in the case of perfect family control (no fertility risks), since output per capita relative to the baseline increases by at most 13 percent. While this is indeed a large measure, it is a small fraction of the difference in income levels between Kenya and more developed or emerging market economies.

\subsection{Supply-side Policies}

The successful strategy of supply-side family planning policies is to make modern contraceptives accessible to as many women as possible. In our model such policies should affect the relative price of contraceptives $\phi_{q}$. Table 8 reports key statistics relative to the baseline 
for a counterfactual experiment in which households can access modern contraceptives without any monetary cost $\left(\phi_{q}=0\right)$. There is still a utility cost $\Psi_{q}$ for using them, but since this estimated utility cost is negligible ${ }^{39}$ the implication is that now all agents choose to fully insure against the fertility risk and there is no unwanted pregnancy or abortion. In this case there is perfect fertility control and effects for this supply-side policy on output, inputs, prices, and inequality are similar to the extreme scenario of no fertility shocks, which was previously discussed. Output per capita increases by 13 percent. This policy costs 2.74 percent of the baseline output per capita. ${ }^{40}$

This supply-side intervention generates a reduction in fertility of 6.86-8.3 percent (depending on whether or not general equilibrium effects are taken into account. see Table A9 in the companion Online Appendix). As reported previously, such numbers are close to the estimates reported in empirical literature (see Table 6). The cost per birth averted corresponds to 7.21 percent of per capita GDP when general equilibrium effects are considered, and 5.97 percent of per capita GDP when they are not. ${ }^{41}$

Another supply-side family planning policy is to offer abortions at no cost in public hospitals and clinics, such that $\phi_{a}=0$. One practical problem with this policy is that abortion is still considered largely illegal in many countries, including Kenya ${ }^{42}$ and most aborted pregnancies are terminated through illegal means. Therefore, before this policy could be implemented abortion laws in Kenya would first need to be relaxed.

With this caveat in mind, we present results of this experiment in the third column of Table 8 . The percent of pregnancies aborted almost doubles since women reduce their use of modern contraceptives. Unwanted fertility decreases by 0.5 of a child and total fertility decreases by 0.30 of a child as a result of this policy. Families adjust their wanted fertility margin once this policy is implemented. ${ }^{43}$ Most of the decrease in fertility is in the lower tail of the education distribution. Average years of schooling for the adult population rises from 7.68 to 8.46 , and there is a 15 percent increase in the level of the capital stock relative to the baseline. As a result, output per capita increases by 9 percent relative to the baseline. Inequality decreases, and most of this reduction is due to relative improvements in the income of households at the lower tail of the income distribution. Given the original price of abortion, the overall cost of this policy is relatively small. It corresponds to 0.47 percent of the baseline output or about 8 percent of the total expenditure on education

\footnotetext{
${ }^{39} \Psi_{q}=0.0024$ and the average utility in the baseline economy is 3.86 .

${ }^{40}$ This implies a long-run multiplier of government expenditures on output per capita of 4.74.

${ }^{41}$ In Subsection D.5 of the Online Appendix we also consider the case in which the price of modern contraceptives $\left(\phi_{q}\right)$ is heterogenous among the adult population in Kenya. We let the price of contraceptives to be $10 \%$ (but also $30 \%$ ) higher than the baseline for households with at most 8 years of schooling and $10 \%$ (but also 30\%) lower for households with more than 8 years of schooling. The idea behind this heterogeneity is that more educated households could not only use modern contraceptives more effectively than less educated households, but they could also have easier access to them - closeness to hospitals, doctors and clinics. Results are qualitatively similar to what we observe in Table 8.

${ }^{42}$ According to Article 26 of the Constitution of Kenya, "Abortion is not permitted unless, in the opinion of a trained health professional, there is a need for emergency treatment, or the life or health of the mother is in danger, or if permitted by any other written law."

${ }^{43}$ The full effect is decomposed into three different channels (general equilibrium movements, wanted fertility margin, and education margin) in Table A9 in the companion Online Appendix.
} 
Table 8: Counterfactual experiments: Supply and demand policies, Kenya 2008

\begin{tabular}{|c|c|c|c|c|c|}
\hline \multirow[b]{2}{*}{ Statistics } & \multirow[b]{2}{*}{ Baseline } & \multicolumn{2}{|c|}{ Supply Policies } & \multicolumn{2}{|c|}{ Demand Policies } \\
\hline & & $\begin{array}{c}\text { Free } \\
\text { contrac. }\end{array}$ & $\begin{array}{c}\text { Free } \\
\text { abortion }\end{array}$ & $\begin{array}{l}\text { No disutil. } \\
\text { of contrac. }\end{array}$ & $\begin{array}{l}\text { No disutil. } \\
\text { of abortion }\end{array}$ \\
\hline \multicolumn{6}{|l|}{ Output, input, and prices } \\
\hline Ypc relat. to the baseline & 1 & 1.13 & 1.09 & 0.99 & 1.05 \\
\hline$K$ relat. to the baseline & 1 & 1.21 & 1.15 & 0.98 & 1.09 \\
\hline Av. years of schooling & 7.68 & 8.78 & 8.46 & 7.65 & 8.09 \\
\hline$w$ relat. to the baseline & 1 & 1.04 & 1.03 & 0.99 & 1.02 \\
\hline$r$ relat. to the baseline & 1 & 0.93 & 0.95 & 1.01 & 0.97 \\
\hline \multicolumn{6}{|l|}{ Fertility and family planning } \\
\hline Av. fertility & 5.54 & 5.16 & 5.25 & 5.58 & 5.35 \\
\hline Av. unwanted fert. & 0.92 & 0 & 0.42 & 0.91 & 0.51 \\
\hline$\%$ of $\mathrm{HHs}$ who use contrac. & 33 & 100 & 12 & 34 & 0 \\
\hline$\%$ of pregn. aborted & 12 & 0 & 22 & 12 & 23 \\
\hline Av. contrac. exp./wh (\%) & 0.28 & 0 & 0.08 & 0.28 & 0 \\
\hline \multicolumn{6}{|l|}{ Inequality and welfare } \\
\hline Gini index & 0.48 & 0.47 & 0.47 & 0.48 & 0.48 \\
\hline Labour income $90 / 50$ & 3.83 & 3.89 & 4 & 3.83 & 3.95 \\
\hline Labour income 90/10 & 12.57 & 10.89 & 10.29 & 12.57 & 12.16 \\
\hline Welfare & 3.86 & 4.11 & 4.02 & 3.85 & 3.96 \\
\hline \multicolumn{6}{|l|}{ Cost of the policy } \\
\hline Cost $/ Y_{p c}($ current $Y),(\%)$ & 0 & 2.43 & 0.43 & - & - \\
\hline $\operatorname{Cost} / Y_{p c}($ original $Y),(\%)$ & 0 & 2.74 & 0.47 & - & - \\
\hline
\end{tabular}

in Kenya. Therefore, with respect to their effects on output per capita, the free abortion policy seems to be more cost-effective than the free contraceptive policy. ${ }^{44}$

There is a limitation in this comparison. When we internally estimated $\phi_{a}$ we took into account the unit price of existing abortions in Kenya, but most of these abortions are taking place in illegal clinics, which can be relatively cheaper than in official providers. Nevertheless, according to Hussain (2012), international charity Marie Stopes performs abortions at prices from $\$ 25$ to $\$ 60$ in Kenya, and relative to per capita output this cost is in the range of what our model predicts for such a measure. In Subsection D1 of the Online Appendix we perform counterfactual policies with higher abortion price. In Subsection D6 of this Appendix we let the utility cost of abortion $\left(\Psi_{a}\right)$ to be heterogenous among the adult population in Kenya. The main idea is that the type of abortion might be very different for low educated women when compared to highly educated women. Health and other risks might be higher for low educated women than for high educated women.

\footnotetext{
${ }^{44}$ The long-run government expenditures multiplier on output per capita in this case is about 5 times higher than in the case of free access to contraceptives.
} 


\subsection{Demand-side Policies}

Another set of family planning interventions are policies aiming to illustrate the positive aspects of contraceptives and their efficacy in birth control. Favourable attitudes and behaviour toward modern contraceptive methods can be achieved through improvements in, and greater male involvement with, family planning knowledge. These changes can in turn be effected through media campaigns and collaboration with community leaders (cf., Ashraf, Field, and Lee, 2014). In our model we implement this by reducing the utility cost of contraceptive use to zero. Table 8 contains some key statistics of such counterfactual experiments, and Table A10 in the Online Appendix reports the decomposition of the full effect. Since our estimated utility cost of modern contraceptive use is small, ${ }^{45}$ we can see that such demand policies would have limited effects on the share of women using modern contraceptives and therefore on reproductive behaviour and real economic variables.

We also run another family planning demand policy in which we reduce the utility cost of abortion. This is a much harder policy to implement in real life: Besides emotional side effects after an abortion, which may be able to be mitigated through counselling or other therapeutic help, there can also be adverse physical consequences associated with it. Therefore, although we think it is worthwhile to execute and report this counterfactual experiment in our model, we know that it would be difficult to implement it in practice. However, the utility cost of abortions can also be related to the fact that abortions are largely illegal in Kenya, as well as to taboos and social stigmas, which can prevent pregnant women from seeking abortion facilities. Given that this estimated cost in our model is much higher than the cost associated with the use of modern contraceptives, the potential effects on reproductive behaviour and on the economy are stronger for a reduction in the utility cost of abortion than a reduction in the utility cost of contraceptives. The percentage of pregnancies terminated when the utility cost of abortion is set at zero doubles relative to the baseline. Given the relative price of contraceptives, we can observe that no woman would choose to use modern contraceptives to control family size. They would rely only on abortion to prevent unwanted births. The average unwanted fertility decreases by 0.4 of a child, and it decreases for all education categories. Realised fertility decreases by 0.19 of a child, which suggests that households adjust wanted fertility upward. Output per capita increases by 5 percent relative to the baseline and inequality is roughly unchanged. The decomposition shows that the wanted fertility margin and the investment education margin are the key channels in driving the overall results. ${ }^{46}$ For obvious reasons, it is difficult to price the cost of such demand policies, which explains why we do not report the costs associated with them, as well as why we will mainly focus on supply-side reforms. Results are qualitatively similar to those reported here.

Our counterfactual experiments so far with supply and demand family planning inter-

\footnotetext{
${ }^{45}$ This might not be the case in other countries. A recent piece from the Economist (2016) shows that in some countries there are still important barriers preventing couples from using modern contraceptives. For instance, "Greeks commonly believe that the pill and other hormonal contraceptives cause infertility and cancer. They also distrust intrauterine devices (IUDs), possibly because they have been taught that tampons are unhealthy." As a result, "in Greece abortion is seen as an ordinary form of birth control."

${ }^{46}$ See Table A10 in the Online Appendix.
} 
ventions suggest clearly that there might be room for such policies to affect fertility and economic outcomes, which is consistent with the micro-level evidence on the impact of family planning policies on household behaviour (cf., Joshi and Schultz, 2013).

\subsection{Birth Control versus Educational Policies}

That family planning interventions can bring benefits to those who make use of them and can generate significant aggregate effects has been shown above. However, policy makers are faced with a menu of different set of policies to choose from and therefore it is important to understand the cost-effectiveness of each policy. For instance, governments might choose to improve access to modern contraceptives and/or invest in education. The efficacy of family planning policies versus educational policies has long been a topic of debate in development economics (cf., Pritchett, 1994; Schultz, 2008). Furthermore, not only is the focus of policies important, but also how they are designed. Policies can be universal, so that the government subsidises education for all children or distributes contraceptives freely to all women; or they can be targeted to specific groups, so that only relatively poor households receive cash transfers for keeping their children at school, or only poor women have free access to modern contraceptives. We now provide different experiments in which we shed some light on this debate.

\subsubsection{Universal Policies}

There are a variety of different policies which can be introduced in our model but for issues related to their implementability in the real world, we will focus on policies which either subsidise access to modern contraceptives, or abortion, or subsidise education. In the first counterfactual policy the government offers a subsidy on the price of modern contraceptives to all women. ${ }^{47}$ The level of this subsidy is such that expenditure on this policy corresponds to 0.5 percent of income. Some statistics of this policy relative to the baseline economy are shown in Table 9. The policy is effective in expanding the use of modern contraceptives since the fraction of women using such methods increases from 33 percent to 84 percent. Although the average fertility decreases by just 0.10 of a child, the effect of this policy on unwanted pregnancy is larger since unwanted fertility decreases by 0.34 of a child ${ }^{48}$ and abortion is reduced by more than half. Human capital and physical capital investments rise as expected, and output per capita increases by roughly 2.7 percent. Subsidies for abortion can generate an even stronger effect on output. As shown previously, free access to abortion for all women would cost about 0.47 of baseline GDP and would increase output per capita relative to the baseline by 9 percent in the long run. This per capita output response is about 3.37 times larger than the effect on output per capita of a subsidy on the price of modern contraceptives

\footnotetext{
${ }^{47}$ The National Health Service (NHS) in England offers free modern contraceptives at an affordable cost to everyone (cf., the Economist, 2016).

${ }^{48}$ We do not report the decomposition of the full effect but such experiments are available upon request.
} 
Table 9: Counterfactual experiments: Universal and targeted policies, Kenya 2008. Universal Policies: Subsidy on the price of modern contraceptives; subsidy on the price of abortion; and subsidy on basic education (0-4 years) for all families. Targeted Policies: Subsidy on the price of modern contraceptives for women with up to 8 years of schooling; subsidy on the price of abortion for women with up to 8 years of schooling; and subsidy on basic education for children with parents with up to 8 years of schooling.

\begin{tabular}{|c|c|c|c|c|c|c|c|}
\hline \multirow[b]{2}{*}{ Statistics } & \multirow[b]{2}{*}{ Baseline } & \multicolumn{3}{|c|}{ Universal Policies } & \multicolumn{3}{|c|}{$\begin{array}{c}\text { Targeted Policies } \\
\text { Parents with up to } 8 \text { yrs of sch. }\end{array}$} \\
\hline & & $\begin{array}{l}\text { Subsid. } \\
\text { contrac. }\end{array}$ & $\begin{array}{l}\text { Subsid. } \\
\text { abortion }\end{array}$ & $\begin{array}{l}\text { Subsid. } \\
\text { education } \\
(0-4 \text { yrs })\end{array}$ & $\begin{array}{l}\text { Parents } \\
\text { Subsid. } \\
\text { contrac. }\end{array}$ & $\begin{array}{l}\text { with up to } 8 \\
\text { Subsid. } \\
\text { abortion }\end{array}$ & $\begin{array}{l}\text { yrs of sch. } \\
\text { Subsid. } \\
\text { education } \\
(0-4 \text { yrs })\end{array}$ \\
\hline \multicolumn{8}{|l|}{ Output, input, and prices } \\
\hline Ypc relat. to the baseline & 1 & 1.027 & 1.091 & 0.977 & 1.025 & 1.087 & 1.033 \\
\hline$K$ relat. to the baseline & 1 & 1.04 & 1.15 & 0.95 & 1.04 & 1.14 & 1.04 \\
\hline Av. years of schooling & 7.68 & 8.78 & 8.46 & 7.84 & 7.85 & 8.41 & 8.36 \\
\hline$w$ relat. to the baseline & 1 & 1.01 & 1.03 & 0.98 & 1.01 & 1.03 & 1.01 \\
\hline$r$ relat. to the baseline & 1 & 0.98 & 0.95 & 1.02 & 0.98 & 0.95 & 0.99 \\
\hline \multicolumn{8}{|l|}{ Fertility and family planning } \\
\hline Av. fertility & 5.54 & 5.44 & 5.25 & 5.73 & 5.45 & 5.25 & 5.52 \\
\hline Av. unwanted fert. & 0.92 & 0.58 & 0.42 & 0.92 & 0.63 & 0.50 & 0.90 \\
\hline$\%$ of HHs who use contrac. & 33 & 84 & 12 & 26 & 73 & 17 & 28 \\
\hline$\%$ of pregn. aborted & 12 & 5 & 22 & 12 & 5 & 20 & 12 \\
\hline Av. contrac. exp./wh (\%) & 0.28 & 0.92 & 0.08 & 0.22 & 1.81 & 0.13 & 0.24 \\
\hline \multicolumn{8}{|l|}{ Inequality and welfare } \\
\hline Gini index & 0.48 & 0.48 & 0.47 & 0.48 & 0.48 & 0.48 & 0.47 \\
\hline Labour income 90/50 & 3.83 & 3.89 & 4 & 3.87 & 3.92 & 4.00 & 4.04 \\
\hline Labour income $90 / 10$ & 12.57 & 12.21 & 10.29 & 12.03 & 12.21 & 10.73 & 12.10 \\
\hline Welfare & 3.86 & 3.91 & 4.02 & 3.89 & 3.90 & 4.01 & 3.98 \\
\hline \multicolumn{8}{|l|}{ Cost of the policy } \\
\hline $\operatorname{Cost} / Y_{p c}($ current $Y),(\%)$ & 0 & 0.50 & 0.43 & 0.50 & 0.50 & 0.35 & 0.50 \\
\hline Cost $/ Y_{p c}($ original $Y),(\%)$ & 0 & 0.51 & 0.47 & 0.49 & 0.51 & 0.38 & 0.52 \\
\hline
\end{tabular}

If the government alternatively funds education so that all children, regardless of family income, have access to the first four years of primary education without any direct private cost, then fertility (due to an income effect) rises substantially by more than a child. Children become relatively cheaper and parents respond to that by having more children. Although schooling also rises and inequality decreases, the net effect on output per capita of this policy is negative. In fact, output per capita would decrease if the government subsidised 4-8 years of education, 8-12 years of education, or 0-12 years of education. The main driver behind this fall in output is the rise in fertility when primary or secondary education is universally subsidised. Output per capita only rises when the government subsidises higher education, but this policy is rather regressive and inequality rises relative to the baseline. From these policy experiments we can conclude that universal subsidies in early education are less effective than public investment in modern contraceptives or abortion to raise per capita income and to control fertility.

The cost-effectiveness of abortion subsidies when compared to the two other policies is robust to (i) the case when the price of abortion is at the highest range observed in Kenya - 
US\$200 instead of US\$59 (see Table A13 in the Online Appendix); and (ii) when the utility cost of abortion is $30 \%$ higher relative to the baseline for households with up to 8 years of schooling and 30\% lower relative to the baseline for households with more than 8 years of schooling (see Table A18 in the Online Appendix).

\subsubsection{Targeted Policies}

Now we focus our analysis on targeted policies. Table 9 reports results for three different targeted policies: a subsidy on the price of modern contraceptives for women with up to 8 years of schooling (a primary degree); a subsidy on the price of abortion for women with up to 8 years of schooling (a primary degree); and a subsidy on basic education (0-4 years) for the children of the parents with up to 8 years of schooling (a primary degree). ${ }^{49}$ The policy would cost up to 0.5 percent of GDP.

A targeted subsidy on the price of modern contraceptives for women with up to 8 years of schooling (a primary degree) increases the share of women using such contraceptive methods, but by less than the universal policy reported previously. The fraction of women using modern contraceptives increases from 33 percent to 70 percent with this policy, but it jumps to 84 percent when the universal policy is implemented. Additionally, average wanted fertility decreases by about 0.09 of a child and the average unwanted fertility by 0.29 of a child. Investment in human and physical capital rise and output per capita increases by roughly 2.5 percent. These numbers are bit less than in the universal policy, which is explained by the fact that in the baseline equilibrium there are also unwanted pregnancies among women with a secondary or a higher degree and a universal policy would increase the intensity of modern contraceptive use for all women, and not only those at the lower tail of the human capital distribution.

Making abortion free for women with up to 8 years of schooling would cost 0.38 percent of baseline output. Compared to the subsidy on modern contraceptive prices for women with the same amount of schooling, the abortion subsidy is much more effective in reducing unwanted fertility and total fertility, and consequently on increasing investment in human and physical capital. This subsidy increases output per capita by 8.7 percent relative to the baseline or about 3.24 times the increase in output per capita when the use of modern contraceptives is subsidised for women with the same amount of schooling.

Finally, the last column of Table 9 reports results for the experiment in which basic education ( $0-4$ years) is subsidised for all children of parents with up to 8 years of schooling. Educational attainment increases, and output per capita relative to the baseline increases by 3.3 percent. Average realised and unwanted fertility are roughly unchanged. Relative to the other two targeted policies, this targeted subsidy on education generates a larger impact on output per capita than the subsidy on the price of modern contraceptives, but smaller effect on income per capita when abortion is subsidised. This ranking of policies by their effectiveness to increase income is robust to when price of abortion is in the

\footnotetext{
${ }^{49}$ We report results for this target group because it is the one in which the subsidy on education generates the largest positive effect on per capita income. Table A14 in the Online Appendix contains results with policies which target women with up to 4 years of schooling.
} 
higher range observed in the data and when the utility cost of abortion is higher for poorer households than for households with higher levels of education.

There are many health complications associated with abortion, which vary significantly with the stage at which the pregnancy is stopped and these might not be fully captured in our model. In addition, official providers in developing countries such as Kenya might not have the facilities, medical specialists and medicines needed in order to scale the level of abortions generated in our experiments. Our experiments just suggest that countries should think about their legal law on abortion and whether or not to provide them in official providers. As discussed previously, in many countries abortion is not permitted by law but still several women undergo unsafe abortions each year. Our experiments also show that contraceptive policies seem to be an effective strategy to not only increase living standard but to also decrease abortions.

\subsection{Ghana}

In order to verify whether or not our model fit and results are specific to the choice of Kenya as the baseline economy, we also estimate model parameters such that we match micro and macro moments of Ghana for 2008. We apply a similar strategy and consider the same moments used in the case of Kenya. Income per capita in Ghana is 40 percent higher than in Kenya and there are other important differences between these two economies. For instance, the abortion rate is higher in Ghana than in Kenya. While abortion in Kenya is prohibited by its Constitution unless the life and health of an expectant mother is in danger, abortion in Ghana is legally permissible. ${ }^{50}$

Table A15 and A16 in the Online Appendix report the calibrated and estimated parameter values that result from the baseline estimation procedure applied to Ghana and the model fit, respectively. For the sake of space we do not report them here. The model does a better job in reproducing the fertility (wanted and unwanted) behaviour for Ghana than for the case of Kenya. Interestingly, the utility abortion cost is estimated to be approximately half of value estimated for Kenya ( $\Psi_{a}=0.0422$ for Ghana instead of $\Psi_{a}=0.0804$ ).

Table 10 reports key statistics relative to the Ghana baseline for a couple of counterfactual experiments. In the first (No fertility shocks) experiment we consider the case in which households can perfectly control family size. Unwanted fertility goes down to 0 and the average fertility goes down by about 0.3 of a child, i.e., total fertility is reduced by approximately 8 percent. This is very close to what we observed to the case of Kenya in which fertility was reduced by 7 percent. Notice that output increases by 10 percent relative to the baseline. It increased by 13 percent in the case of Kenya.

In the second extreme experiment households can control fertility by only adjusting wanted fertility. The average fertility increases by 1.3 of a child relative to the baseline, while unwanted fertility increases from 0.55 to 2.39 . Output decreases by 28 percent. The difference in output per capita between an economy without any modern control of fertility to another in which there is perfect control of family size is approximately 38 percent.

\footnotetext{
${ }^{50}$ Countries Where Abortion Is Illegal Population. Retrieved 2019-09-09, from http://worldpopulationreview.com/countries/countries-where-abortion-is-illegal/
} 
Table 10: Counterfactual experiments: Extreme cases and supply policies, Ghana 2008

\begin{tabular}{|c|c|c|c|c|c|}
\hline \multirow[b]{2}{*}{ Statistics } & \multirow[b]{2}{*}{ Baseline } & \multicolumn{2}{|c|}{ Extreme cases } & \multicolumn{2}{|c|}{ Supply Policies } \\
\hline & & $\begin{array}{c}\text { No fertility } \\
\text { shocks }\end{array}$ & $\begin{array}{l}\text { No family } \\
\text { planning }\end{array}$ & $\begin{array}{c}\text { Free } \\
\text { contrac. }\end{array}$ & $\begin{array}{c}\text { Free } \\
\text { abortion }\end{array}$ \\
\hline \multicolumn{6}{|l|}{ Output, input, and prices } \\
\hline Ypc relat. to the baseline & 1 & 1.10 & 0.72 & 1.10 & 1.06 \\
\hline$K$ relat. to the baseline & 1 & 1.21 & 0.55 & 1.21 & 1.13 \\
\hline Av. years of schooling & 7.34 & 8.25 & 5.31 & 8.25 & 7.98 \\
\hline$w$ relat. to the baseline & 1 & 1.05 & 0.86 & 1.05 & 1.03 \\
\hline$r$ relat. to the baseline & 1 & 0.91 & 1.31 & 0.91 & 0.94 \\
\hline \multicolumn{6}{|l|}{ Fertility and family planning } \\
\hline Av. fertility & 3.66 & 3.36 & 4.94 & 3.36 & 3.47 \\
\hline Av. unwanted fert. & 0.55 & 0 & 2.39 & 0 & 0.20 \\
\hline$\%$ of $\mathrm{HHs}$ who use contrac. & 16 & 0 & 0 & 100 & 8 \\
\hline$\%$ of pregn. aborted & 30 & 0 & 0 & 0 & 37 \\
\hline Av. contrac. exp./wh (\%) & 0.14 & 0 & 0 & 0 & 0.04 \\
\hline \multicolumn{6}{|l|}{ Inequality and welfare } \\
\hline Gini index & 0.51 & 0.50 & 0.51 & 0.50 & 0.51 \\
\hline Labor income 90/50 & 3.51 & 3.32 & 3.59 & 3.32 & 3.33 \\
\hline Labor income 90/10 & 16.04 & 15.93 & 15.56 & 15.93 & 14.25 \\
\hline Welfare & 4.73 & 4.90 & 4.31 & 4.89 & 4.83 \\
\hline \multicolumn{6}{|l|}{ Cost of the policy } \\
\hline Cost $/ Y_{p c}($ current $Y),(\%)$ & 0 & 0 & 0 & 2.07 & 0.25 \\
\hline $\operatorname{Cost} / Y_{p c}($ original $Y),(\%)$ & 0 & 0 & 0 & 2.29 & 0.27 \\
\hline
\end{tabular}

This difference is about 8 percentage points larger than the case observed for Kenya.

Table 10 also reports statistics for a counterfactual experiment in which households can access modern contraceptives without any monetary cost. There is still a utility cost for using them. As in the case of Kenya, the estimated utility cost is negligible and all agents choose to fully insure against the fertility risk. There is no unwanted pregnancy or abortion. Therefore, results are similar to the case of perfect fertility control. The cost of this policy is 2.29 percent of the baseline output, which implies a long-run multiplier of government expenditures on output per capita of 4.36 .

We also implement a family planning policy to offer abortions at no cost in public hospitals and clinics, such that $\phi_{a}$ is equal to zero. Output per capita increases by 6 percent relative to the baseline. The overall cost of this policy is relatively small. It corresponds to approximately 0.27 percent of the baseline output. The long-run government expenditures multiplier on output per capita in this case is about 5 times higher than in the case of free access to contraceptives. This difference is similar to the one observed for Kenya.

Finally, instead of calibrating and estimating model parameters to different economies, which is computationally demanding and time consuming, we also create the following 
counterfactual economies: (i) we adjust the total factor productivity parameter $A$ of Equation (1) such that the counterfactual economy has a relative (to Kenya) per capita income similar to what is observed in the data for some reference economies; and (ii) in the spirit of de la Croix and Doepke (2003), we also adjust proportionally the cost of education $\lambda(e)$, such that the cost of education relative to income per capita remains unchanged. The idea is that teachers' salary should be positively related to per capita income. The value of the other parameters are kept at the level estimated for Kenya. There are 9 counterfactual economies based on income data from Congo, Ghana, Egypt, Liberia, Sao Tome and Principe, Sierra Leone, Tanzania, Uganda and Zambia. The poorest economy in this sample is Liberia. Its per capita income is 38 percent of the the level observed in Kenya. The richest economy is Egypt, which is approximately 4 times richer than Kenya.

Subsection D4 of the Online Appendix provides the effects of two family planning interventions using these counterfactual economies. The two interventions are: (a) Experiment in which the price of modern contraceptives is zero $\left(\phi_{q}=0\right)$; and $(b)$ there is no monetary cost of abortion $\left(\phi_{a}=0\right)$. Clearly, the effects of supply-side family planning policies on aggregate variables such as income per capita, average years of schooling and the average fertility rate are decreasing with income levels. This is expected since for these counterfactual economies we are keeping the cost of modern contraceptives and abortion at the level observed in Kenya. Therefore, for economies with higher TFP, modern contraceptives and abortion are relatively more affordable. Free modern contraceptives (abortion) increase(s) income per capita in approximately 17\% (24\%) in the counterfactual economy with GDP per capita similar to the one observed in Liberia and $4 \%(3 \%)$ in the counterfactual economy with GDP per capita similar to the one observed in Egypt. Recall that even when the aggregate effects are small, family planning interventions might have important distributional impacts on fertility and human capital formation.

\section{Conclusions}

The role of family planning policies in endogenously affecting fertility, savings, human capital investment, and income per capita levels has not been explored in the macro literature. Conventional macroeconomics wisdom ascribes family size to demand or the quantity-quality trade-off, which implies that family planning interventions should not have major impact on the economy (cf., Pritchett, 1994). This view has a major shortcoming: micro development literature shows that improving knowledge and access to modern contraceptives, and legalising abortion can have important effects on individual outcomes (cf., May, 2012). Our paper contributes to the existing literature by embedding endogenously unwanted fertility in a standard quantity-quality overlapping generations model of population and growth with heterogenous households. Our model has several novel characteristics: Fertility control is costly and families can (partially) insure against a fertility risk by using costly contraception. Households can opt to abort some unwanted pregnancies, at a cost. Given the number of children born, parents decide how much education to provide and how much to save out of their young adulthood income. The model 
is calibrated and estimated to match key empirical moments of the economy of Kenya.

We show that the standard macro view that family size is determined by demand is in part correct since aggregate fertility is mainly driven by desired family size. The difference between the fertility rate of our baseline (2008 Kenyan economy) model, in which fertility is costly controlled, and a model in which fertility is fully controlled through costless contraceptives is just 0.4 of a child. However, access to modern contraceptives and abortion shapes the compositional pattern of fertility and consequently, the human capital dynamics and savings of a society, and family planning interventions can have sizeable effects on individual outcomes and aggregate variables. The average fertility measure hides important distributional issues since the gap between realised and wanted fertility can be three times larger for low-income families than high-income families. Our counterfactual exercises show that if modern contraceptive methods are freely provided to all women, then output per capita would increase by 13 percent relative to the baseline economy, and that would cost about 2.43 of GDP. Interestingly, our results suggest that with a small government budget (say, up to 0.5 percent of GDP), family planning interventions might be more cost-effective in improving long-run living standards than polices that subsidise education. In practice, family planning interventions might be also more effective when integrated to raise awareness about contraceptives and to change social norms through education (sexual education) polices.

Our fertility model can be applied to investigate important unresolved questions such as the role of access to modern contraceptives in affecting structural transformation, female labor force participation, and social security. Future research can potentially address these and other related questions.

\section{References}

Ashraf, N., E. Field, AND J. LeE (2014): “Household Bargaining and Excess Fertility: An Experimental Study in Zambia," American Economic Review, 104(7), 2210-2237. 5, 6, 11,30

Ashraf, Q. H., D. N. WeIL, AND J. Wilde (2013): “The Effect of Fertility Reduction on Economic Growth," Population and Development Review, 39(1), 97-130. 6

Bailey, M. J., O. Malkova, and Z. M. Mclaren (2017): “Does Parents' Access to Family Planning Increase Children's Opportunities? Evidence from the War on Poverty and the Early Years of Title X," NBER Working Paper 23971. 23

BARRO, R. J., AND G. S. BECKer (1989): "Fertility Choice in a Model of Economic Growth," Econometrica, 57(2), 481-501. 2, 5

Baudin, T., D. DE LA CROIX, AND P. E. GobBi (2016): “Endogenous Childlessness and Stages of Development," Working Paper, University Catholoque de Louvain. 5

BEACH, B., AND W. W. HANLON (2019): “Censorship, Family Planning, and the Historical Fertility Transition," NBER Working Paper No. 25752. 5 
BECKER, G. S. (1960): "An Economic Analysis of Fertility," in Demographic and Economic Change in Developed Countries, ed. by G. B. Roberts, Chairman, Universities-National Bureau Committee for Economic Research, pp. 209-240. Columbia University Press. 2, $5,12,27$

BECKER, G. S., AND H. G. LEWIS (1973): “On the Interaction between the Quantity and Quality of Children," Journal of Political Economy, 81(2), S279-S288. 5

BHATTACHARYA, J., AND S. CHAKRABORTY (2017): "Contraception and the Demographic Transition," Economic Journal, 127(606), 2263-2301. 5

Bloom, D. E., D. Canning, G. FinK, and J. E. Finlay (2009): “Fertility, Female Labor Force Participation, and the Demographic Dividend," Journal of Economic Growth, 14(2), 79-101. 6

BOngaARTS, J. (2016): “Development: Slow Down Population Growth," Nature, 530(7591), 409-412. 2

DAsGuPtA, P. (2000): "Reproductive Externalities and Fertility Behaviour," European Economic Review, 44(4-6), 619-644. 2

De LA Croix, D., And M. Doepke (2003): “Inequality and Growth: Why Differential Fertility Matters," American Economic Review, 93(4), 1091-1113. 5, 17, 36

De Magalhães, L., and R. SAntaeulàlia-Llopis (2018): “The Consumption, Income and Wealth of the Poorest: An Empirical Analysis of Economic Inequality in Rural and Urban Sub-Saharan Africa for Macroeconomist," Journal of Development Economics, 134, 350-371. 25

De Silva, T., And S. Tenreyro (2017): "Population-Control Policies and Fertility Convergence," Journal of Economic Perspectives, 31(4), 205-228. 6

(2019): "The Fall in Global Fertility: A Quantitative Model," Forthcoming American Economic Journal: Macroeconomics. 5, 24

DoePKe, M. (2015): "Gary Becker on the Quantity and Quality of Children," Journal of Demographic Economics, 81(1), 59-66. 5

DoepKe, M., And F. KindermanN (2019): “Bargaining over Babies: Theory, Evidence, and Policy Implications," American Economic Review, 9, 3264-3306. 11

Feenstra, R. C., R. InKLaAR, And M. Timmer (2015): “The Next Generation of the Penn World Table," American Economic Review, 105(10), 3150-3182. 15, 16

FISHER, A. (2016): "Dangerously Cheap: Kenya's Illegal Abortions," aljazeera.com. Retrieved from: https://www.aljazeera.com/indepth/features/2016/10/dangerouslycheap-kenya-illegal-abortions-161027075859609.html. 20 
Galor, O., And M. Klemp (2015): “The Biocultural Origins of Human Capital Formation," Working Paper, Brown University. 3

Galor, O., AND D. N. WeIL (2000): “Population, Technology, and Growth: From Malthusian Stagnation to the Demographic Transition and Beyond," American Economic Review, 90(4), 806-828. 2, 5

Golosov, M., L. E. Jones, And M. TerTilt (2007): “Efficiency with Endogenous Population Growth," Econometrica, 75(4), 1039-1071. 25

Greenwood, J., A. Seshadri, and G. VAndenbroucke (2005): “The Baby Boom and Baby Bust," American Economic Review, 95(1), 183-207. 12, 15

Himes, N. E. (1936): Medical History of Contraception. George Allen \& Unwin Ltd. 3

Hussain, R. (2012): "Abortion and Unintended Pregnancy in Kenya," Rerpot, Guttmacher Institute. 20, 29

Jones, L. E., A. Schoonbroodt, And M. Tertilt (2010): “Fertility Theories: Can They Explain the Negative Fertility-Income Relationship?," in Demography and the Economy (National Bureau of Economic Research Conference Report), ed. by J. Shoven, pp. 43-100. University of Chicago Press. 15

JOSHI, S., AND T. P. SCHUltZ (2013): “Family Planning and Women's and Children's Health: Long-Term Consequences of an Outreach Program in Matlab, Bangladesh," Demography, 50(1), 149-180. 23, 31

KeARnEy, M. S., And P. B. Levine (2009): "Subsidized Contraception, Fertility, and Sexual Behavior," Review of Economics and Statistics, 91(1), 137-151. 23

KREMER, M., AND C. M. Syder (2015): “Preventives vs. Treatments," Quarterly Journal of Economics, 130(3). 12

Levine, P. B., D. Staiger, T. J. Kane, And D. J. Zimmerman (1999): “Roe v Wade and American fertility," American Journal of Public Health, 89(2), 199-203. 24

Malthus, T. (1798): An Essay on the Principle of Population. J. Johnson, London. 2

MAY, J. F. (2012): World Population Policies: Their Origin, Evolution, and Impact. Springer. 24, 36

Migiro, K. (2011): "Kenya Backstreet Abortions Kill Thousands Each Year," Reuters. Retrieved from: http://www.reuters.com/article/us-kenya-backstreet-abortionsidUSTRE79O4XV20111025. 20

MilleR, G. (2010): “Contraception as Development? New Evidence from Family Planning in Colombia," Economic Journal, 120(545), 709-736. 6, 23, 24 
MilleR, G., AND K. S. BABIARZ (2016): “Family Planning Program Effects: Evidence from Microdata," Population and Development Review, 42(1), 7-26. 21

Mohamed, S. F., C. Izugbara, A. M. Moore, M. Mutua, E. W. Kimani-Murage, A. K. Ziraba, A. BanKole, S. D. Singh, and C. Egesa (2015): “The Estimated Incidence of Induced Abortion in Kenya: A Cross-Sectional Study," BMC Pregnancy and Childbirth, 15(185), 1. 20

Phillips, J. F., A. A. BAWAH, AND F. N. BinKA (2006): “Accelerating Reproductive and Child Health Programme Impact with Community-Based Services: the Navrongo Experiment in Ghana," Bulletin of the World Health Organization, 84(12), 949-955. 23

Phillips, J. F., E. F. Jackson, A. A. Bawah, B. Macleod, P. Adongo, C. Baynes, AND J. WILliAMS (2012): “The Long-Term Fertility Impact of the Navrongo Project in Northern Ghana," Studies in Family Planning, 43(3), 175-190. 23

PritchetT, L. H. (1994): “Desired Fertility and the Impact of Population Policies," Population and Development Review, 20(1), 1-55. 8, 24, 27, 31, 36

RobBins, M. (2013): “Kenya's Slum Abortions Pit God Against Death," Vice. Retrieved from: http://www.vice.com/read/kenya-slum-abortions-religion-illegal. 20

Schoellman, T. (2012): "Education Quality and Development Accounting," Review of Economic Studies, 79(1), 388-417. 17

SCHUltz, T. P. (2008): “Population Policies, Fertility, Women's Human Capital, and Child Quality," in Handbook of Development Economics, ed. by T. P. Schultz, and J. Strauss, vol. 4. Elsevier. 31

StruliK, H. (2017): “Contraception and Development: A Unified Growth Theory," International Economic Review, 58(2), 561-584. 5

THE Economist (2016): “How to Make It Rarer," The Economist, December 3rd. 30, 31

THE WORLD BANK (2010): Unmet Need for Contraception. The World Bank, Washington, DC. 3

(2015): World Development Indicators. The World Bank, Washington D.C. 15, 16

USAID (2010): “The Cost of Family Planning in Kenya," Technical report, USAID, Health Policy Initiative. 20

VoGL, T. (2016): "Differential Fertility, Human Capital, and Development," Review of Economic Studies, 83(1), 365-401. 5

Voigtländer, N., AND H.-J. Voth (2013): “How the West 'Invented' Fertility Restriction," American Economic Review, 103(6), 2227-2264. 2

Westoff, C. F. (2008): “A New Approach to Estimating Abortion Rates," DHS Analytical Studies No. 13.16 